\title{
Biodiversity impacts of bioenergy crop production: a state-of-the-art review
}

\author{
DESIRÉE J. IMMERZEEL, PITA A. VERWEIJ, FLOOR VAN DER HILST and ANDRÉ P. C. FAAIJ \\ Group Energy \& Resources, Faculty of Geosciences, Copernicus Institute of Sustainable Development, Utrecht University, \\ Budapestlaan 6, Utrecht, 3584 CD, The Netherlands
}

\begin{abstract}
The use of biomass as feedstock for energy is often associated with increased claims on land, competition with food production and impacts on other ecosystem services. Studies on sustainability aspects of bioenergy production often indicate biodiversity as a key concern. This article presents a first comprehensive review of published impacts of bioenergy crop production on biodiversity, evaluates the drivers and pressures of biodiversity change and summarizes current trends and impacts. The review provides insight into the types of biodiversity indicators applied under a range of conditions and the mitigating measures proposed to minimize negative impacts or realize biodiversity benefits. The 53 selected publications give diverse results that are explained by the various spatial scales, production systems and regions, time horizons, methodologies and biodiversity indicators used. Reported impacts depend on initial land use and are mostly negative, especially in tropical regions. The impacts of second generation bioenergy crops tend to be less negative than first generation ones, and are in some cases positive (at the field level), in particular in temperate regions. Land-use change appears as the key driver of biodiversity change, whereas the associated habitat loss, alterations in species richness and abundance are the main impacts addressed. Such changes are often paired with the (initiation of a) process of biological homogenization. The article confirms that concerns about the expansion of bioenergy crop production not only relate to the direct effects on biodiversity by replacing natural vegetation, but increasingly to indirect effects as well. These effects have, however, shown to be difficult to quantify. At the same time, the land sparing vs. land sharing debate receives growing attention, whereas little evidence exists in bioenergy literature on the impacts of large-scale application of these strategies on (agro)biodiversity. Following the findings of the review, the article finally provides recommendations for future research.
\end{abstract}

Keywords: biodiversity, bioenergy, biomass, impacts, land-use change, review

Received 9 November 2012; revised version received 18 January 2013 and accepted 1 February 2013

\section{Introduction}

The use of biomass for energy can replace fossil fuels, and contribute to greenhouse gas mitigation, security of energy supply and rural development. Currently, renewable energy sources contribute $13 \%$ to the total primary energy supply, of which almost $80 \%$ (50 EJ) is supplied by biomass. Estimates indicate that the global deployment of energy from biomass is expected to increase to 100 - 300 EJ by 2050, a two to sixfold increase compared with current figures. In these estimates, a growing proportion of second generation biofuels is projected (Chum et al., 2011). The production of bioenergy crops can result, however, in increased claims on land, competition with food production and impacts on other ecosystem services. One of the key sustainability concerns related to the growing demand for bioenergy

Correspondence: D. J. Immerzeel, tel. +31 65313 4940, fax +31 30 253 7601, e-mail: desiree.immerzeel@gmail.com refers to the impacts of large scale biofuel feedstock cultivation on biodiversity (Dornburg et al., 2010; Chum et al., 2011; Wicke et al., 2012). The article follows the formal definition of biodiversity of the Convention on Biological Diversity (CBD) stating that "biological diversity means the variability among living organisms from all sources including, inter alia, terrestrial, marine and other aquatic ecosystems and the ecological complexes of which they are part; this includes diversity within species, between species and of ecosystems." Biodiversity is fundamental to ecosystem functioning and contributes directly (through provisioning, regulating and cultural ecosystem services) and indirectly (through supporting ecosystem services) to human well-being (CBD, 2010).

Biofuel feedstock cultivation may affect biodiversity through a variety of driving forces including land-use change, overexploitation, pollution, invasive species and climate change (MEA, 2005; Dornburg et al., 2010). Biodiversity gains and losses can both occur as a result of 
bioenergy crop production depending on, for example, the spatial scale, type of production system, geographical region or time horizon considered. Besides, the effects of biomass production may be either direct (i.e., natural or non-natural habitats being converted into energy crops) or indirect (i.e., natural vegetation being converted into land-use types that are displaced by energy crop production elsewhere) (Smeets et al., 2008; Wicke et al., 2012).

Several national and international studies have been published that evaluate or study the sustainability of bioenergy crop production (e.g., van Dam et al., 2008; Smeets et al., 2008; Dornburg et al., 2010; Beringer et al., 2011; Chum et al., 2011; Walter et al., 2011; Wicke et al., 2012). Publications on the biodiversity effects of bioenergy crop production give diverse results and show that currently no widely accepted methodology is available to quantify these effects (van Dam et al., 2008; Smeets et al., 2008; Dornburg et al., 2010). Some reviews typically focus on biodiversity impacts in a particular region and for specific crop(s) (e.g., Fitzherbert et al., 2008; Dauber et al., 2010; Hartman et al., 2011). To date, a comprehensive review including different geographical regions and crops has not been published. Such a review is, however, considered important to (1) inform decision makers about the biodiversity effects from bioenergy crop production as published in scientific literature, (2) report to sustainability initiatives and certification processes on these effects and provide guidelines for monitoring and (3) develop a research agenda based on identified gaps in knowledge.

This article aims to cover these issues and presents a review of scientific publications on the impacts of biofuel feedstock cultivation on biodiversity. The article evaluates the drivers of biodiversity change associated with bioenergy crop production and summarizes current trends and impacts. In addition, the article provides insight into the types of biodiversity indicators used and the conditions under which these indicators are applied. The review also presents an overview of proposed mitigating measures to minimize negative impacts or realize biodiversity benefits. Following the findings of the review, the article finally provides recommendations for future research in this field of bioenergy science.

\section{Methodology}

The literature on biodiversity impacts of bioenergy crop production is subject to a wide range of definitions and methodologies that are difficult to compare. To structure the findings systematically, the review uses the DPSIR framework (Smeets \& Weterings, 1999). This allows for a clear description of the relationships between increasing demands for bioenergy, expansion of bioenergy cropland, impacts on biodiversity and (proposed) mitigating measures. Following the DPSIR framework, social and economic developments (Driving Forces, D) exert Pressures (P) on the environment and, as a consequence, the State (S) of the environment changes. This leads to Impacts (I) on ecosystems which may elicit a societal Response (R) that feeds back on Driving Forces, State or Impacts via various mitigation or adaptation actions (Smeets \& Weterings, 1999; Maxim et al., 2009). The framework has been widely used for systematic reviews of environmental impact assessments and scientific literature (see Maxim et al., 2009; Haberl et al., 2009; Spangenberg et al., 2009 for some recent examples in the field of biodiversity).

The Web of Science and Science Direct databases were queried for studies published in literature between 2007 and May 2012. An internet search was also performed using the meta-search engine Google scholar. The search terms included combinations of biomass, bioenergy, biodiversity, impacts, effects, benefits and the major biofuel feedstocks (oil-, sugar-, starch- and lignocellulosic crops following Chum et al., 2011). Only impact studies with quantified impacts were selected to allow for evaluation of the types of indicators used and related changes. This implies that the more descriptive or qualitative studies were excluded from the review. To be able to assess changes in biodiversity, studies should include at least one (potential) biofuel crop with a 'reference' or initial habitat, consisting of a natural (e.g., primary forest), low-intensity (e.g., pasture) landuse or traditional (food) crop; or a comparison of at least two (potential) biofuel crops. In addition, metaanalyses and published reviews of biodiversity impacts of certain crops (in specific regions) resulting from the search were evaluated. The overall results of these studies were included and their references were scanned for additional publications fitting the above criteria.

Part of the divergence in methodologies and indicators used in literature is caused by the fact that there is no single indicator that captures the full complexity of biodiversity. This complicates aggregation and comparison and hampers quantitative analysis. Therefore biodiversity impacts are categorized into negative (-), positive $(+)$ and neutral or both negative and positive impacts $(+/-)$.

\section{The spectrum of biodiversity impact studies in bioenergy literature}

The 53 selected publications with quantified biodiversity effects of bioenergy crop production give diverse results (see Table 1 for a full overview). Figure 1 shows the spectrum of studies including the number publications 


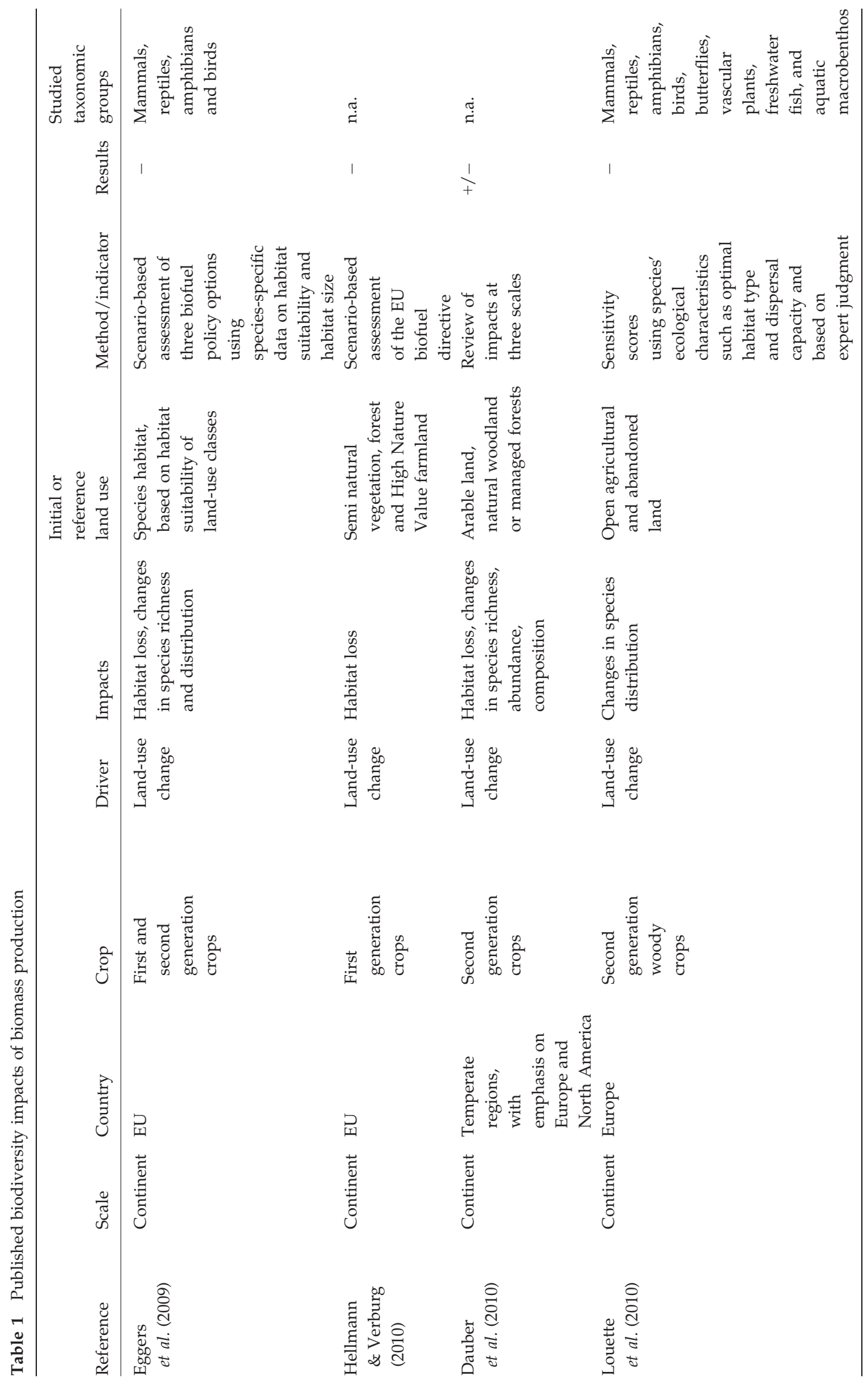




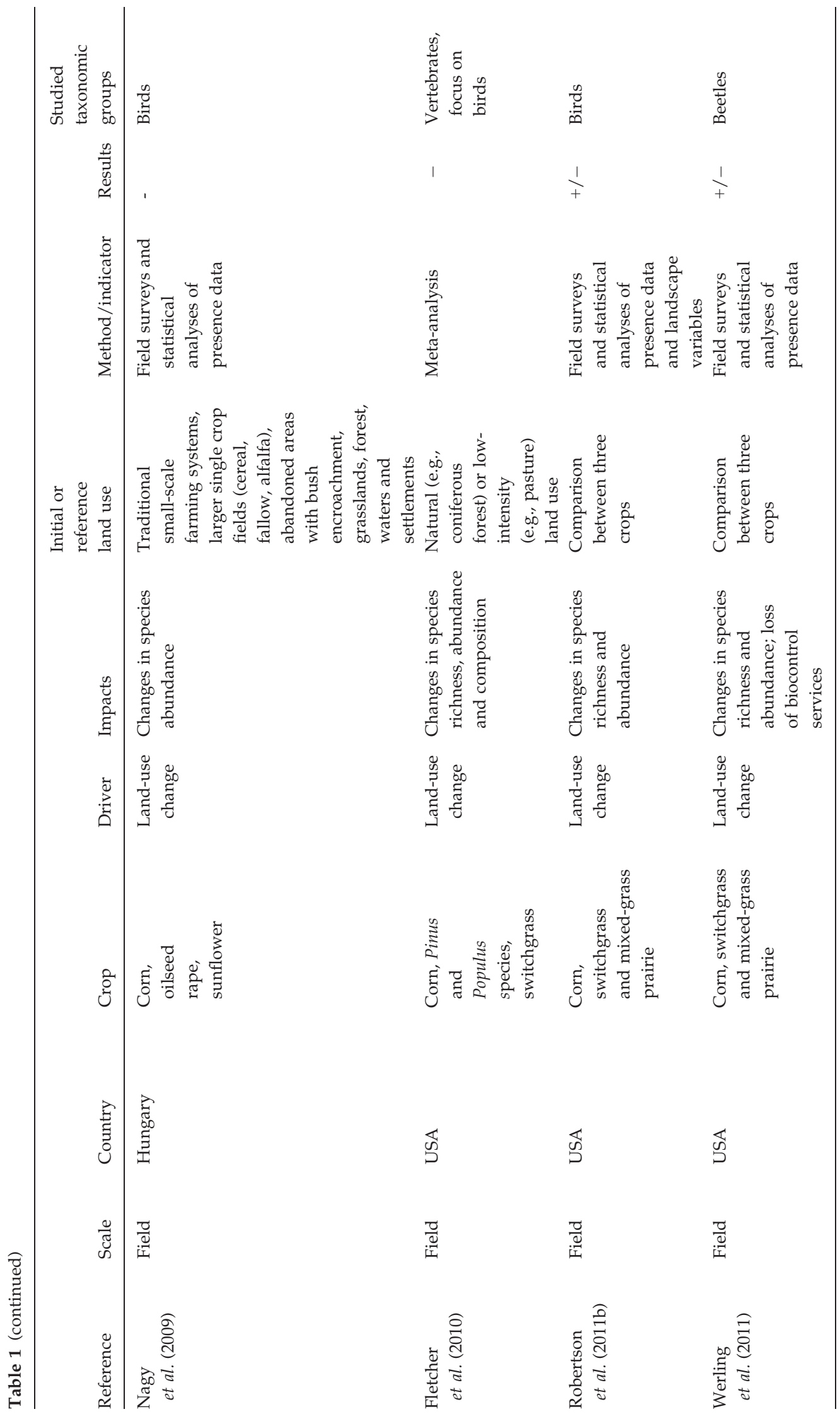




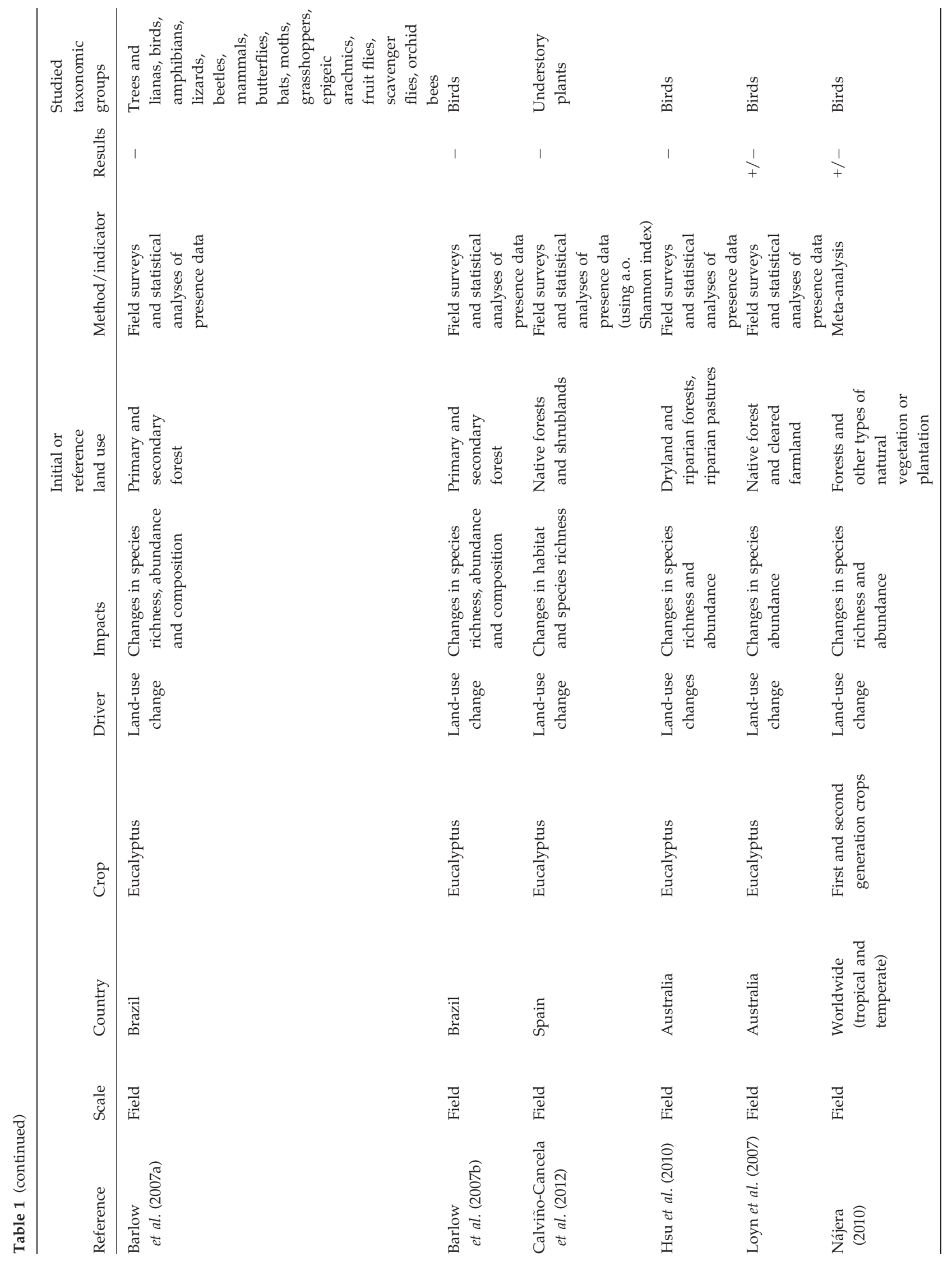




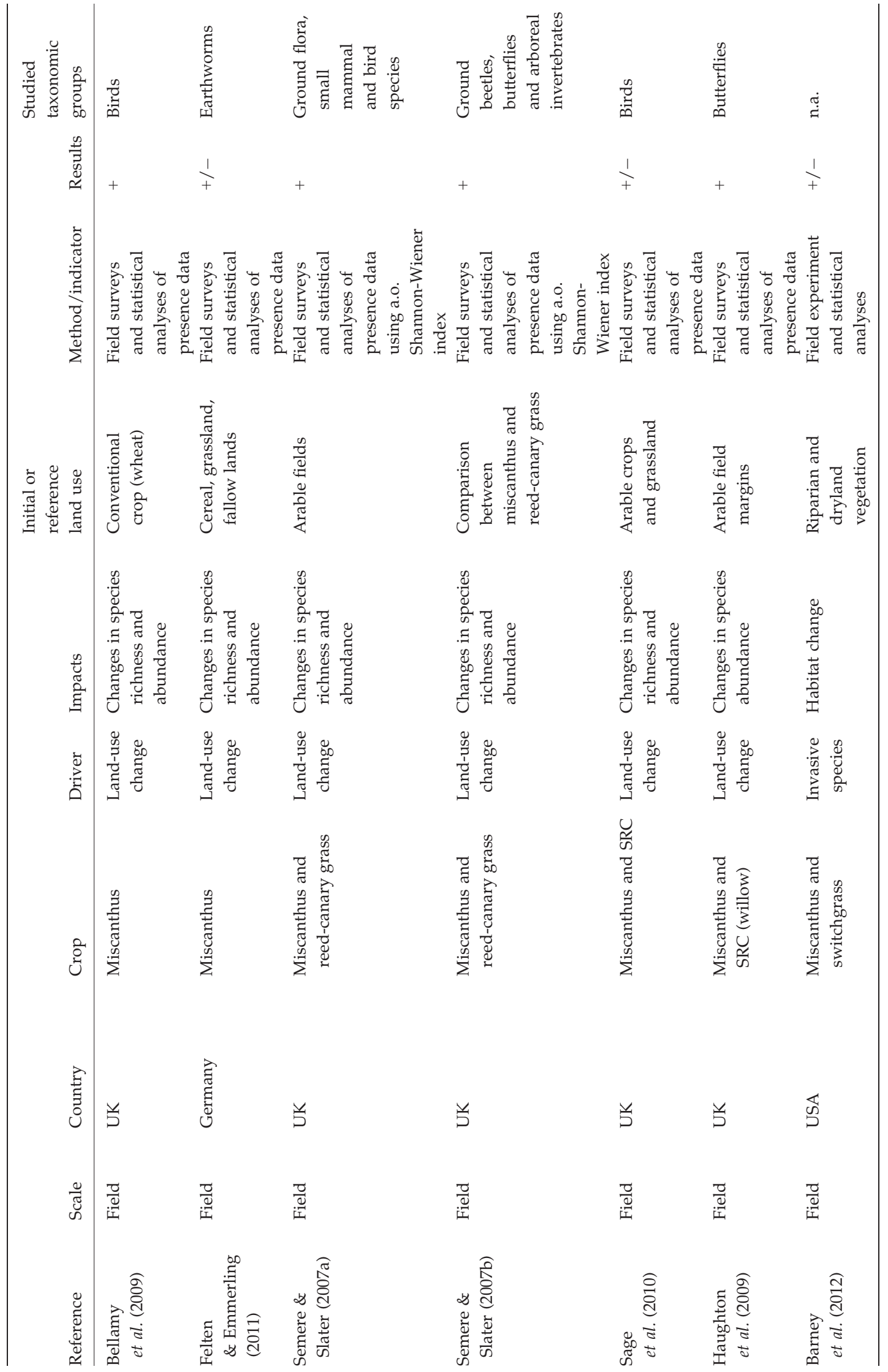




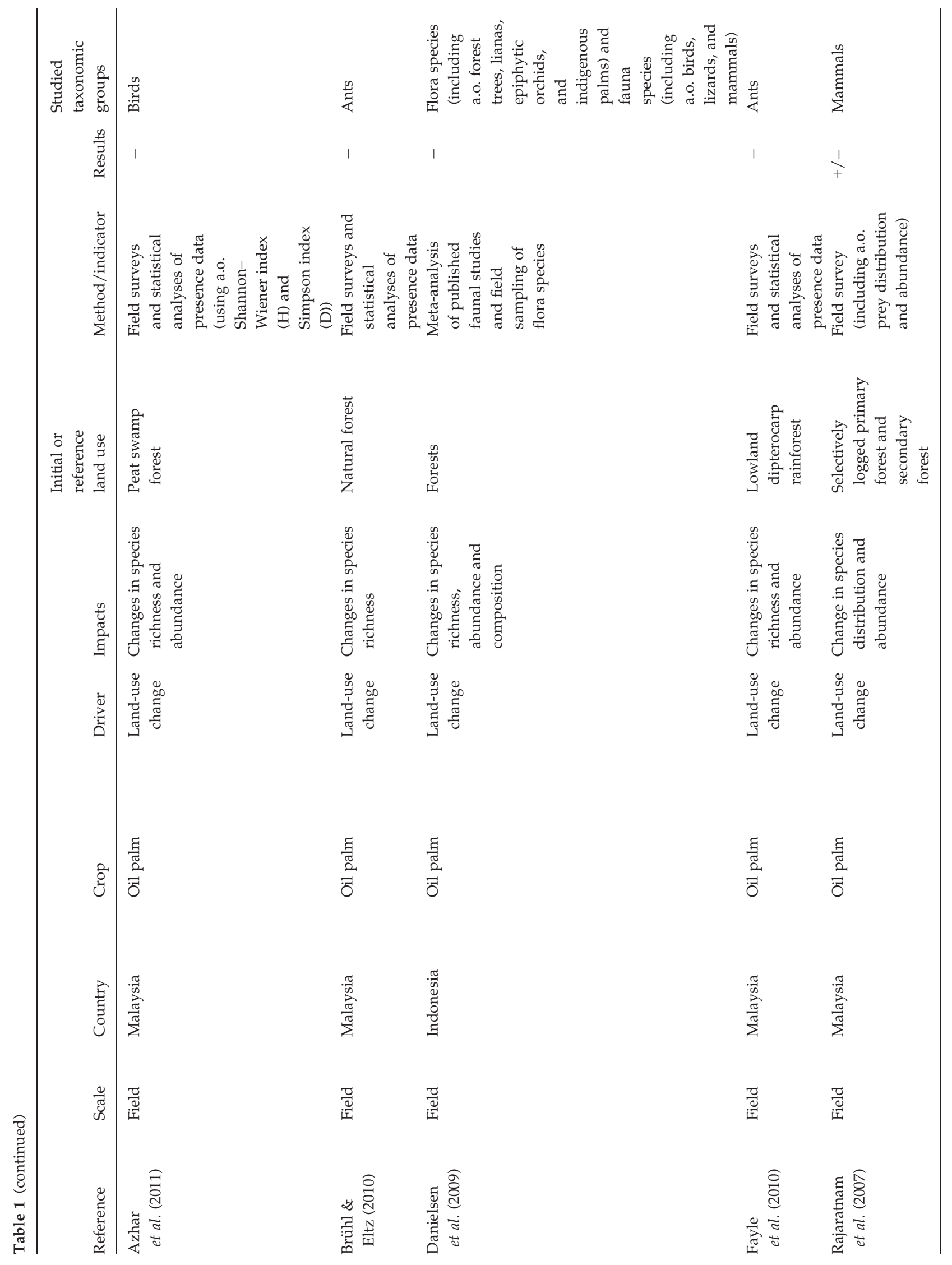




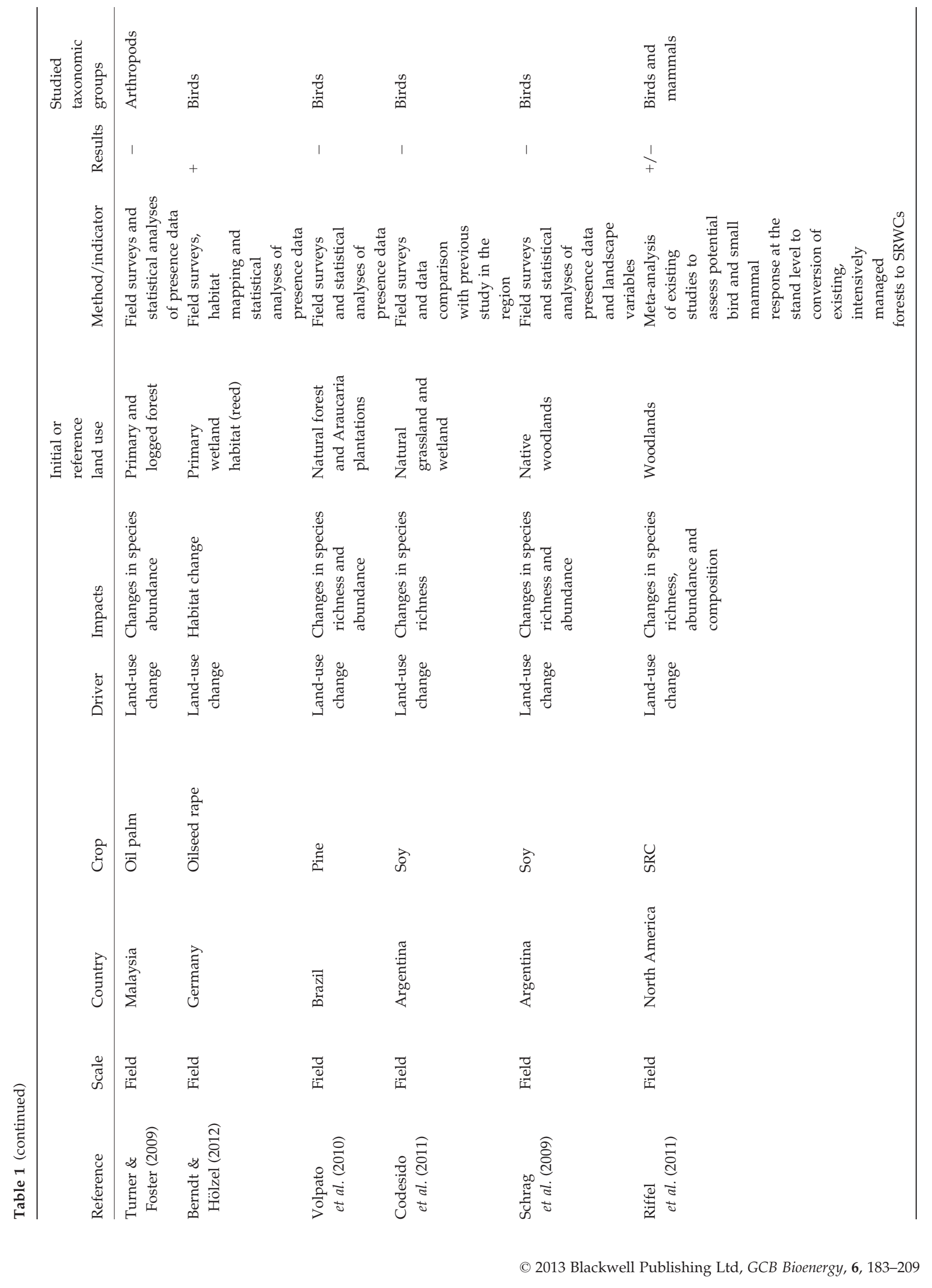




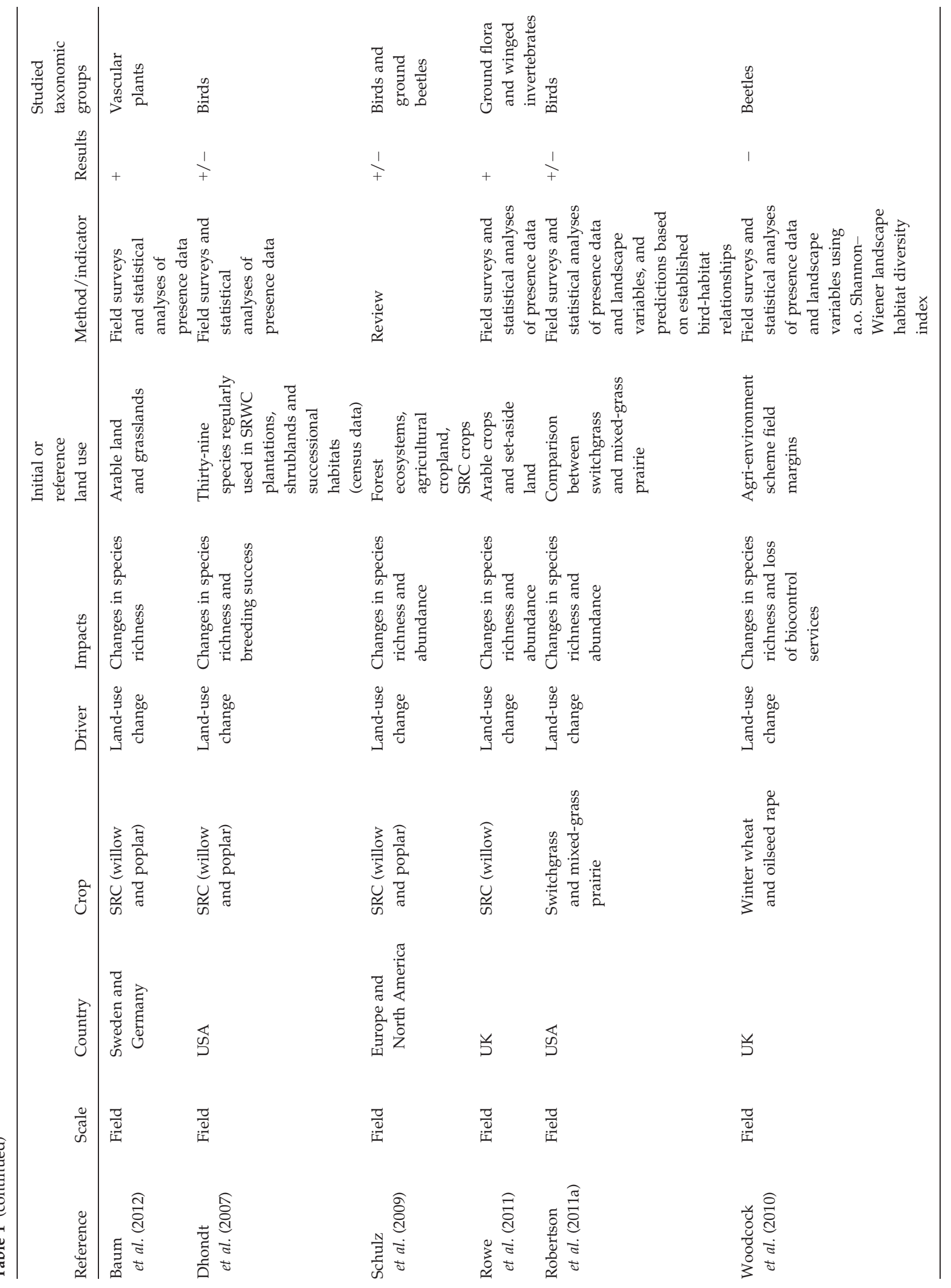




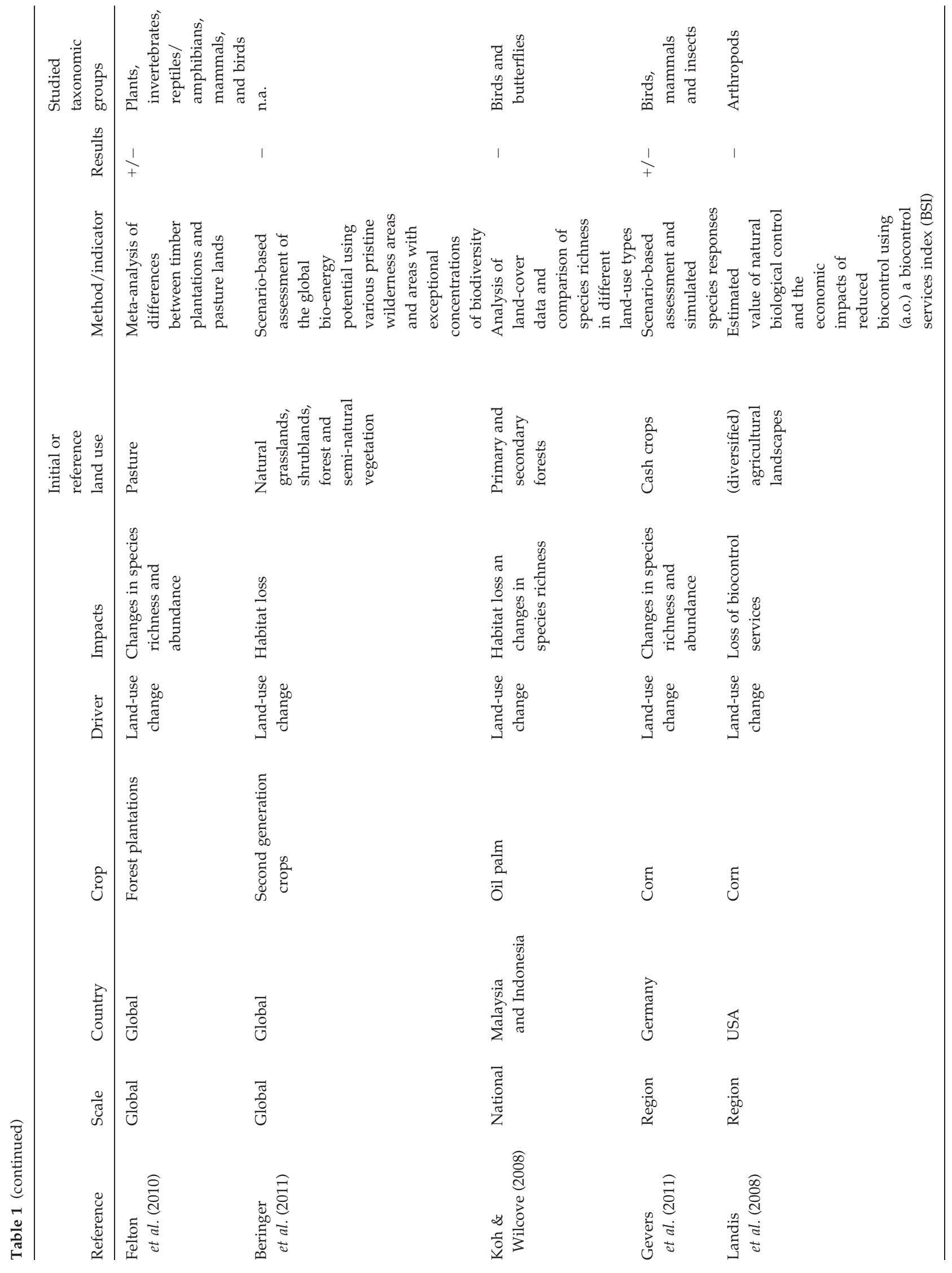




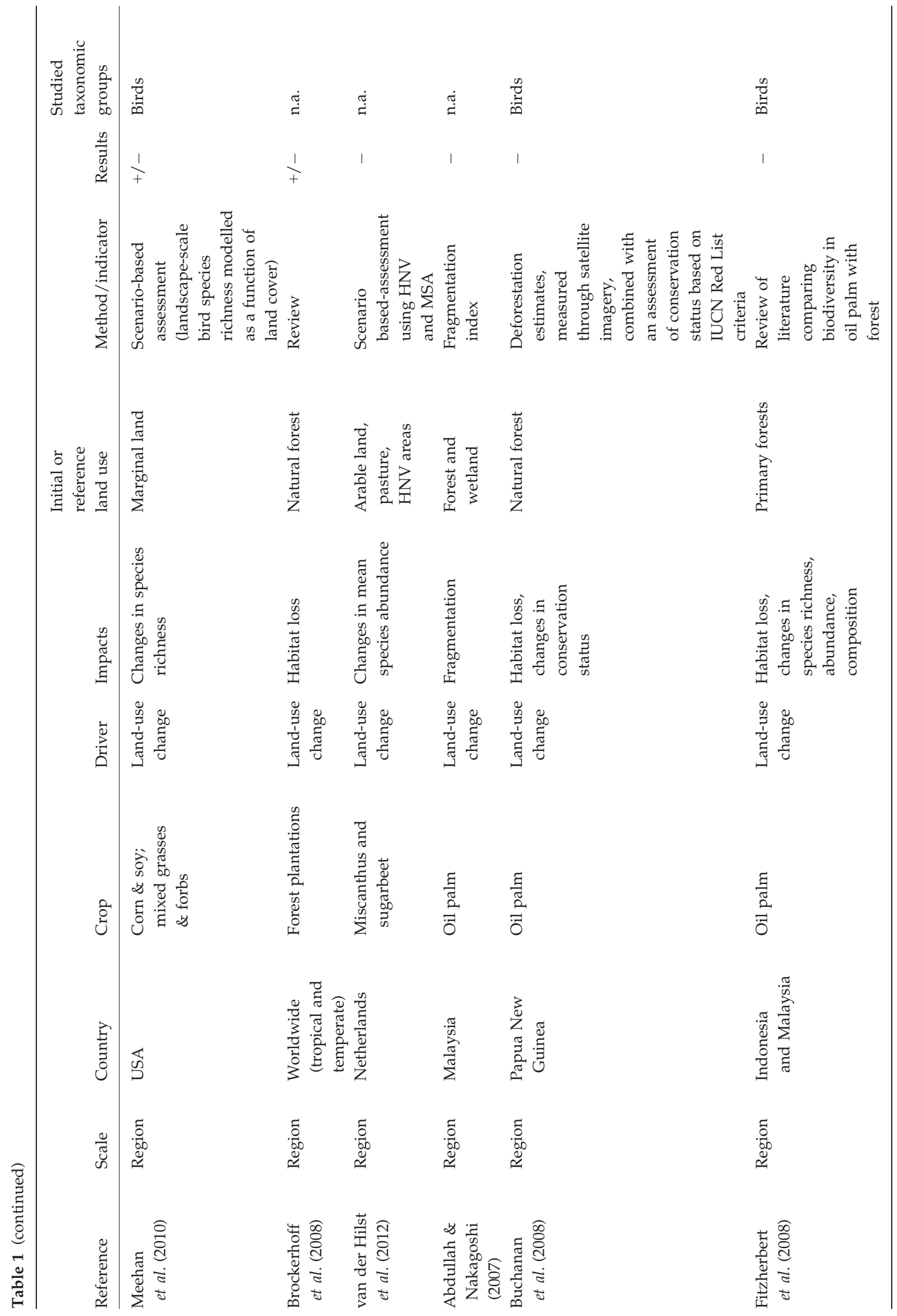




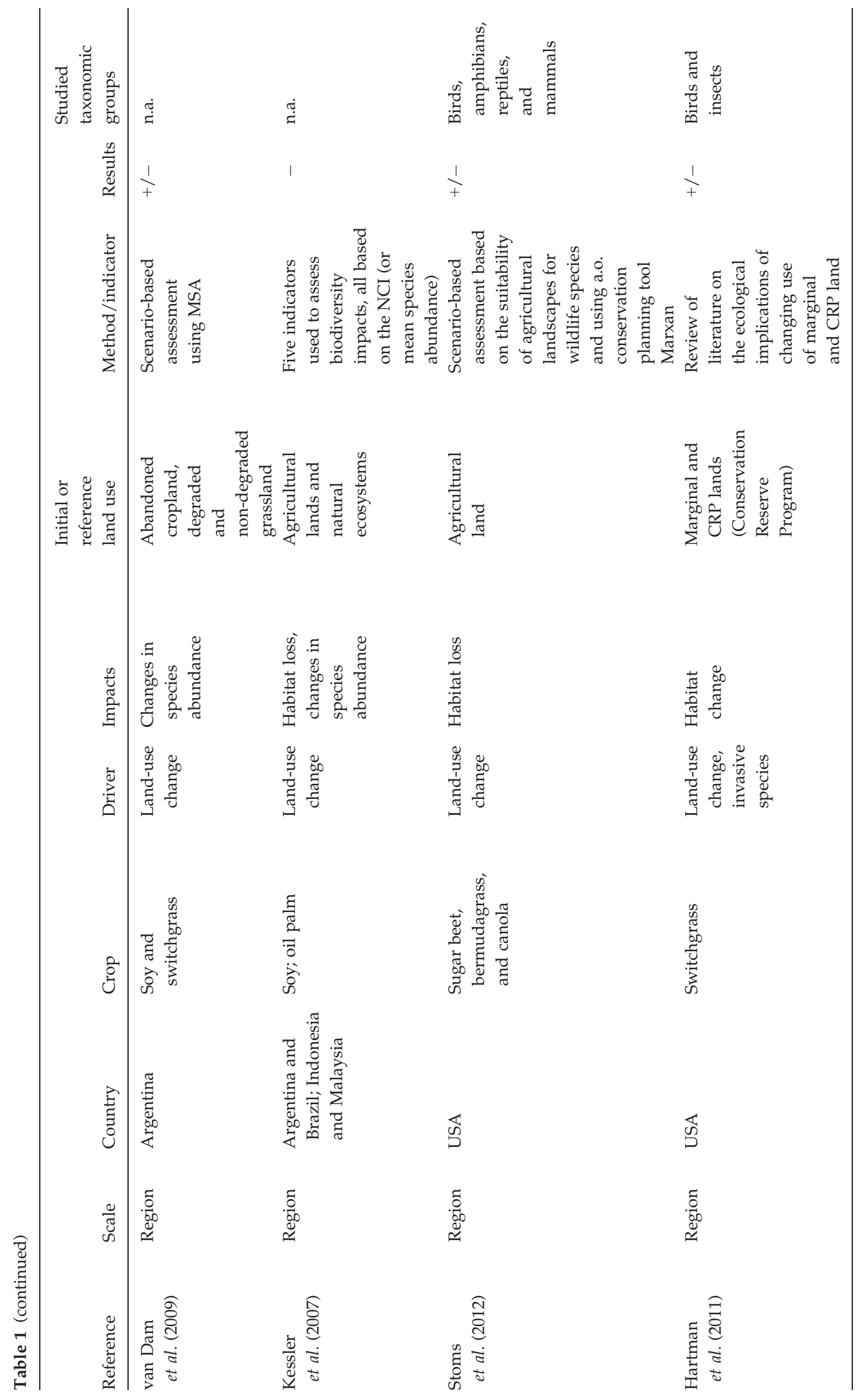




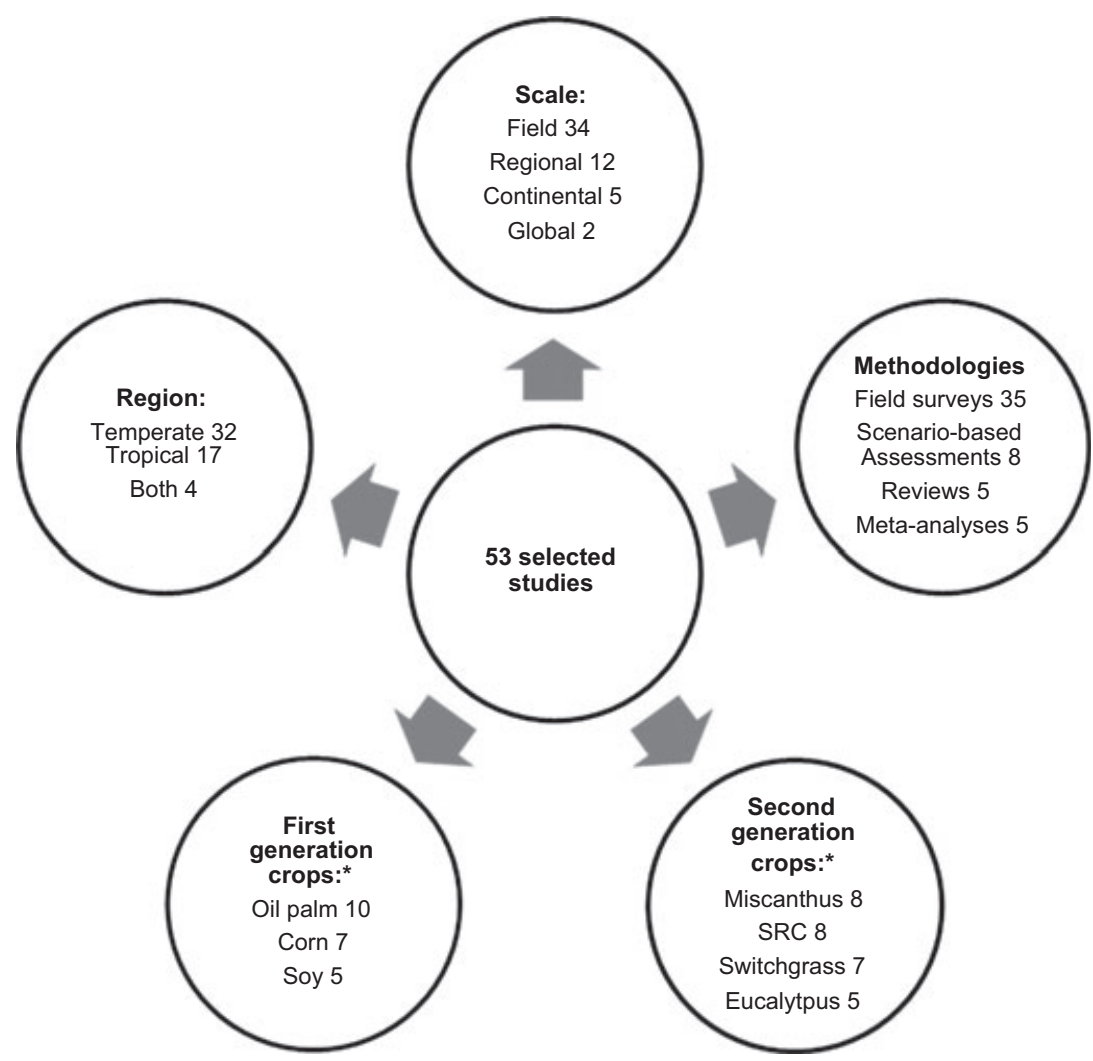

Fig. 1 The spectrum of biodiversity impact studies in bioenergy literature. *More studies focus on second generation crops than first generation crops ( 26 vs. 17 respectively), whereas 10 studies analyze both. Other feedstocks addressed include oilseed rape, sugarbeet, sunflower, wheat, prairie, reed canary grass and other grasses.

per spatial scale, geographical region, type of crop and methodologies applied.

\section{Drivers and pressures}

In the past 50 years, the most important direct driver of biodiversity change in terrestrial ecosystems has been land use and land cover change (MEA, 2005; CBD, 2010; WWF, 2012). Not surprisingly, almost all research on biodiversity impacts of bioenergy crop production focuses on land-use change. The associated habitat loss and fragmentation are the major pressures on biodiversity. Various studies show that concerns about the expansion of biomass production not only relate to the direct effects from converting natural or non-natural habitats into bioenergy crop plantations, but also to the indirect land-use change effects of biofuel feedstock cultivation (e.g., Kessler et al., 2007; Eggers et al., 2009; Hellmann \& Verburg, 2010). Indirect land-use changes (iLUC) can occur when a) direct displacement of pasture or cropland results in livestock or crops being produced elsewhere to continue to meet demand and $b$ ) the diversion of crops to other uses triggers higher crop prices, which results in more land being taken into agricultural production elsewhere (Wicke et al., 2012). Although literature estimating iLUC-induced GHG emissions is growing (e.g., Dornburg et al., 2010; Chum et al., 2011; Wicke et al., 2012), quantification of the indirect effects of biomass production on biodiversity is difficult and has been attempted by few of the selected studies. For example, Hellmann \& Verburg (2010) indicate on a European level that the area of semi natural vegetation, forest and High Nature Value (HNV) farmland converted directly is small in all scenarios variants related to the biofuel directive. The indirect effects of the directive on European land use and biodiversity are, however, much larger. The area of semi natural vegetation is found to be 3-8\% smaller in scenarios with the directive as compared with scenarios without the directive. This is due to replacement of these areas by grassland or arable land compensating for the cultivation of bioenergy crops in other areas. Kessler et al. (2007) calculated the 'multiplier effect' in various tropical countries from commodity development until 2005, which means the additional land-use change as a collateral effect outside the actual cropping areas. They expressed this effect in terms of decrease in Natural Capital Index (an indicator for changes in original species composition). 
The highest multiplier effects occur for soy production in Brazil $(87 \%$ decrease in NCI caused by soy production) and for palm oil in Indonesia (35\% decrease in NCI caused by palm oil production). Figure 2 shows the mechanisms involved in the multiplier effect for the case of Brazil. Although such results are paired with large uncertainties, they give an indication of iLUC expressed in terms of an established biodiversity indicator.

Two studies address the introduction of perennial bioenergy crops as a driver of change in biodiversity due to invasive traits (Hartman et al., 2011; Barney et al., 2012). The crops are being cultivated from non-native taxa to have few resident pests, to tolerate poor growing conditions and to produce competitive bioenergy crops (Barney \& Ditomaso, 2008). The invasive potential of most bioenergy crops and the susceptibility to the invasion of certain habitat types to bioenergy crop species are, however, largely unknown (Barney et al., 2012). Only one field-based assessment by Barney et al. (2012) aimed at analyzing habitat susceptibility and resistance to invasion by perennial grasses in potential receiving environments.

An important driver that is not addressed as such by the selected studies is the intensification of production systems. Intensification is one of the focal points in the bioenergy sector to reduce the competition between food, feed and fuels, and therefore iLUC (Dornburg et al., 2010; Wicke et al., 2012). The amount of bioenergy that can be produced without expanding the total agricultural land-use area depends on the rate of intensification of the agricultural sector and the suitability of the land that becomes available for energy crop production (van der Hilst et al., Forthcoming). Growing attention goes therefore to production of dedicated bioenergy crops on so-called surplus land (two different origins of surplus land are distinguished by Dauber et al. (2012): (1) land currently not in use for the production of food, animal feed, fibre or other renewable resources due to poor soil fertility or abiotic stress and (2) land currently no longer needed for food and feed production because of intensification and rationalization of production, resulting in yield increases and thus a reduced requirement for land), whereas the production of food is continued on established agricultural land (Dauber et al., 2012). This might reduce pressure on sensitive habitats. However, current estimates of availability and suitability of surplus land for development of energy crop production or use of existing biomass potentials are uncertain.

Although the consequences of such developments on biodiversity are only discussed to a limited extent in the

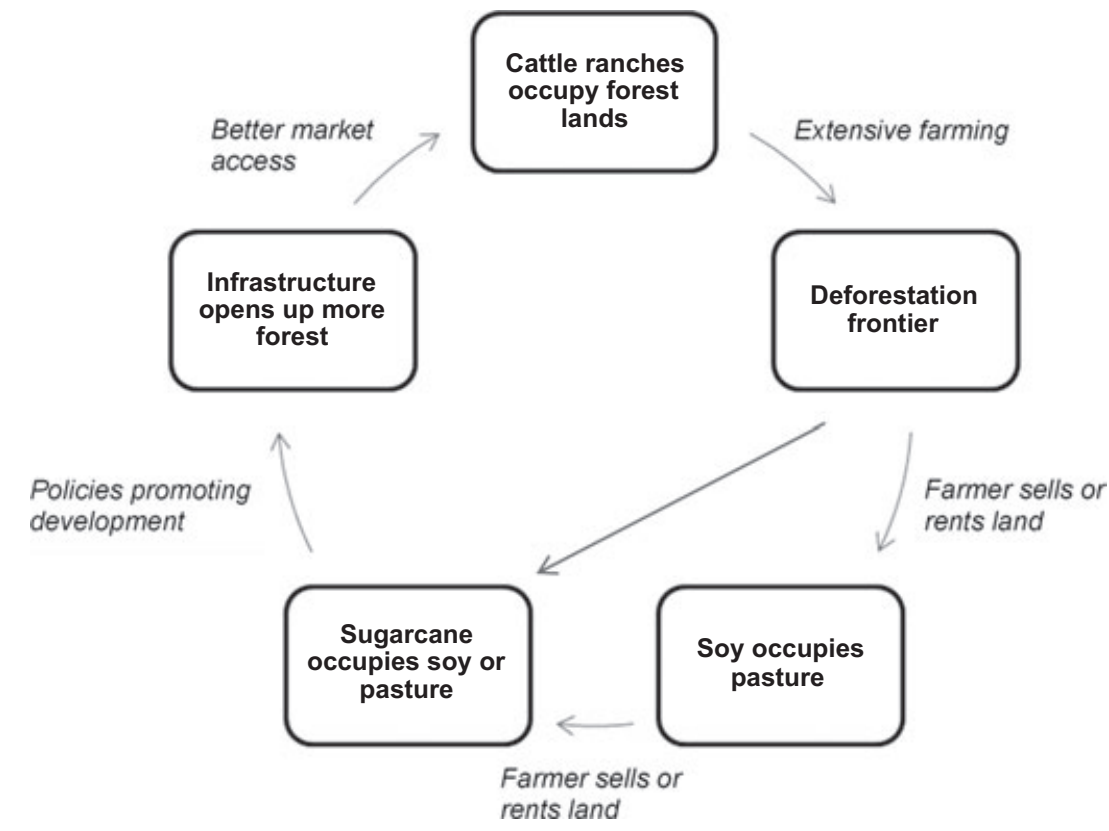

Fig. 2 An example of the multiplier effect as analyzed by Kessler et al. (2007). The Figure is based on Verweij et al. (2009) and schematically shows the complex interactions between agriculture expansion and cattle ranching in the agricultural frontier region between the Amazon and Cerrado biomes in Brazil. Historically, the dominant pattern of forest conversion begun with small-scale exploration for timber or subsistence agriculture, followed by consolidation into large scale cattle ranching operations or abandonment to secondary forest (Morton et al., 2006). The expansion of large-scale mechanized agriculture (mainly soy and increasingly sugarcane) has introduced a new pathway for loss of natural vegetation, generating debate on the contribution of (bioenergy) cropland expansion to deforestation dynamics (Verweij et al., 2009; Sparovek et al., 2012). 
selected studies, intensification of agricultural production receives considerable attention in biodiversity science (outside bioenergy literature). Besides, the current land sparing vs. land sharing debate is growing as well (e.g., Fischer et al., 2008; Phalan et al., 2011; AndersonTeixeira et al., 2012; Tscharntke et al., 2012). Land sparing is the segregation of land for nature and for production and land sharing (or wildlife-friendly farming) is the integration of both objectives on the same land (Tscharntke et al., 2012).

Although intensification of agricultural production systems and the use of surplus land might alleviate pressure on natural ecosystems, it can increase pressure on (agro)biodiversity through a growing share of highyielding monocultures in the landscape and pollution resulting from increased use of fertilizers and pesticides (Sala et al., 2009). This article follows Jackson et al. (2007) stating that "Agrobiodiversity refers broadly to the biota, e.g., soil microbes and fauna, weeds, herbivores, carnivores, etc., colonizing the agroecosystem and surviving according to the local management and environment." Contrary, positive changes can be expected when an intensive land use is replaced by a less intensive one. Introduction of perennial habitats into intensive agricultural systems, also through, for example, agroforestry systems such as alley cropping of SRC trees, might lead to biodiversity benefits such as gains in habitat and higher connectivity (e.g., Porter et al., 2009; Dauber et al., 2010; Holzmeuller \& Jose, 2012).

Results in this debate are still contradictory. Authors increasingly argue, however, that so far the land sparing approach has failed to take into account the multiple ecosystem services provided by extensively managed agricultural landscapes (Porter et al., 2009; Tscharntke et al., 2012). This shows that in the field of bioenergy, major scientific challenges remain regarding agricultural intensification, suitability of (surplus) land and the associated pressures on biodiversity.

A long-term driver that has not been assessed by the selected studies includes climate change effects from bioenergy use. In the long term, bioenergy crop production is expected to contribute to a reduction in GHG emissions and it could therefore lead to a reduction in the effects of climate change on biodiversity (Brink et al., 2007; CBD, 2010; Dornburg et al., 2010). The balance of climate change effects was analyzed by CBD (2010) in a global scenario study in which the target of mitigating climate change by limiting $\mathrm{CO}$ eq concentration to $450 \mathrm{ppm}$ is met by using mainly woody biomass for large scale bioenergy production. In this scenario, the 'positive' effect is that biodiversity, as indicated by the MSA, would decrease by $10 \%$ between 2000 and 2050, compared with $11 \%$ in the baseline scenario.

\section{Drivers and pressures summarized}

Figure 3 presents an overview of the relationships between drivers and pressures of biodiversity changes discussed above. Habitat loss and fragmentation are presented here as pressures on biodiversity resulting from land-use change (also following the formal definition of the Millennium Ecosystem Assessment (MEA) (MEA, 2005)). Most studies use habitat loss (and in a few cases fragmentation), however, as an indicator for biodiversity impacts. Reported results on habitat loss and fragmentation are therefore further discussed in the impacts section below.

\section{Impacts}

In this section, categorized impacts are summarized and for the main indicators, trends and key examples per indicator are described. Reported impacts are mostly negative (26 studies) but particularly depend on spatial scale, geographical region, type of bioenergy crop and initial land use.

\section{Different impacts per spatial scale and geographical region}

Figure 4 shows the biodiversity impacts on different spatial scales. On each scale, the majority of the impacts are negative. Positive impacts are only reported at the field scale. It is, however, difficult to draw general conclusions here, as the number of studies is strongly biased towards the field scale. This might indicate that benefits at the larger geographical scales are more difficult to obtain, but more research at these scales is required to underpin such conclusions. This could particularly be the case for second generation crops in temperate regions, where the acreage of those crops is still too small to identify coarse scale impacts on biodiversity.

As shown in Fig. 5, the expansion of bioenergy crops in the tropics raises most concerns with $88 \%$ of studies reporting negative impacts, especially for first generation crops (mainly oil palm and soy).

\section{The importance of initial land use}

The majority of negative impacts refer to the conversion of natural vegetation to first generation crops, in particular in the tropics. Koh \& Wilcove (2008) report, for example, that between 1995 and 2005, 55-59\% of oil palm expansion in Malaysia and at least 56\% in Indonesia occurred at the expense of primary forest. As indicated by Gasparatos et al. (2011), reviews on the biodiversity impacts from oil palm expansion have shown that oil palm plantations contain much fewer 


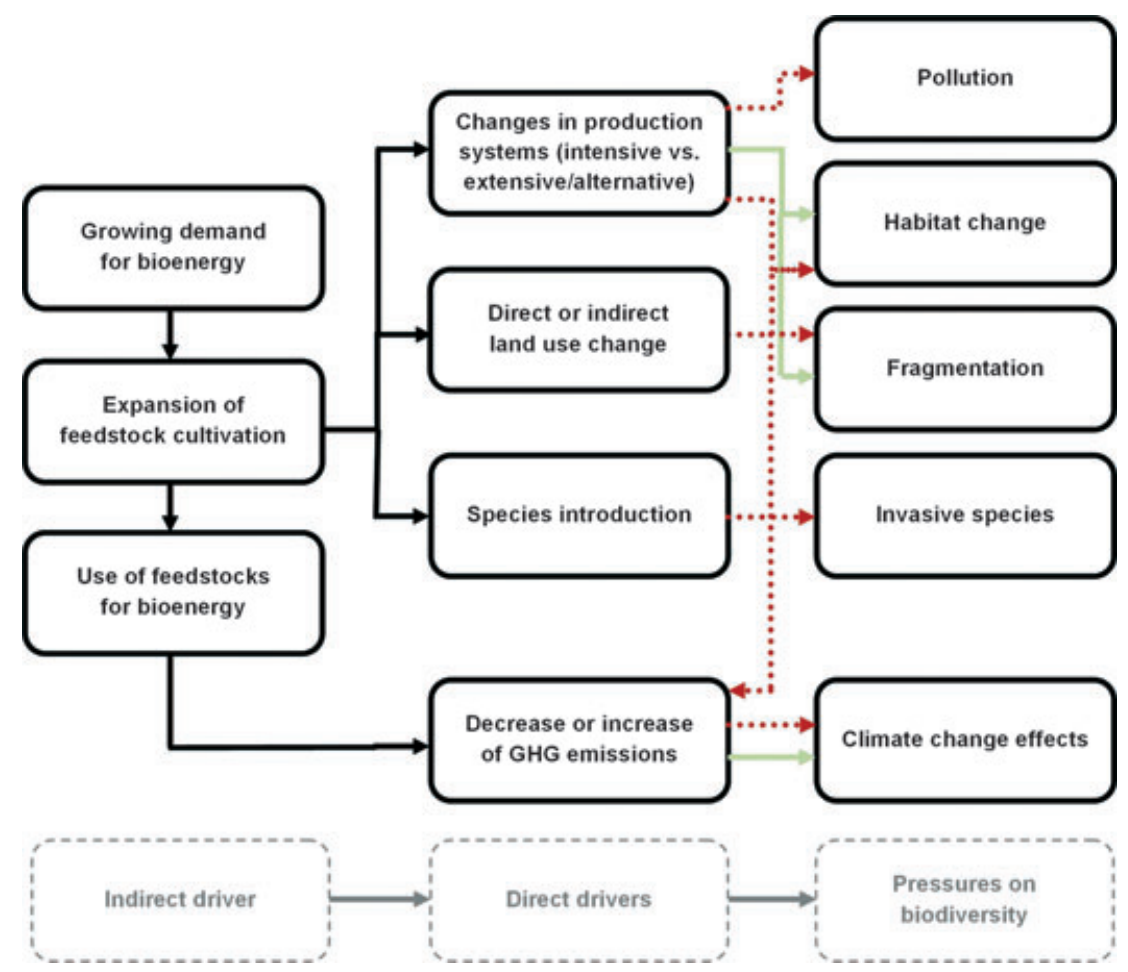

Fig. 3 Relationships between drivers and pressures of biodiversity change resulting from bioenergy crop production. Negative influence: $\cdots . . .>$ Positive influence: $\longrightarrow$.

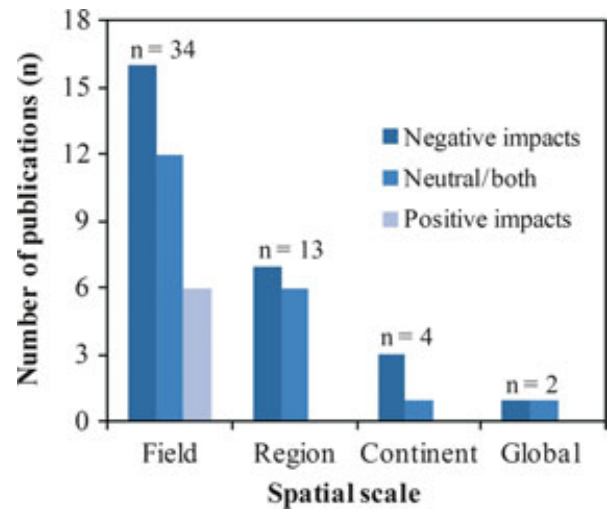

Fig. 4 Biodiversity impacts on different spatial scales. One national study is included under region in the figure. Regional scale is defined here as a region within a country.

species than primary forests (e.g., Fitzherbert et al., 2008; Danielsen et al., 2009). Besides, the subsequent communities were dominated by a few generalist species of low-conservation value (Danielsen et al., 2009). The studies suggest that biodiversity loss in oil palm plantations occurs because plantations are structurally less complex than primary forests, have a shorter life span and are major landscape fragmentation factors (Fitzherbert et al., 2008; Gasparatos et al., 2011).

The evidence of negative impacts not only refers to the conversion of primary or secondary forests but also

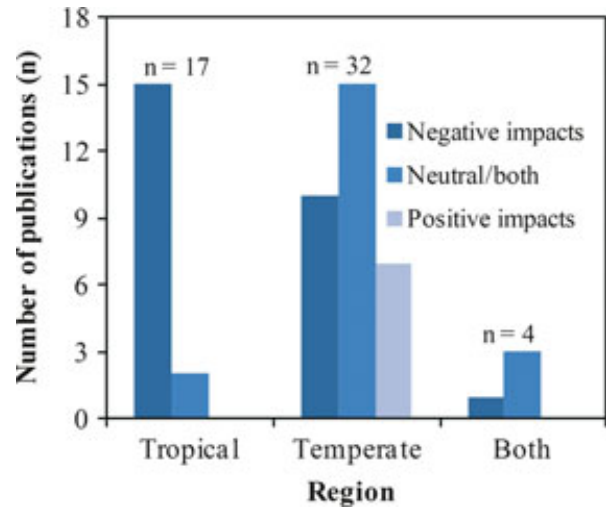

Fig. 5 Biodiversity impacts per production region.

to the conversion of other natural ecosystems including grasslands, wetlands or other areas of high biodiversity value. However, when abandoned cropland, degraded or marginal lands are converted, biodiversity benefits are reported in both tropical and temperate regions, especially in relation to second generation crops. Caution is, however, needed when making general assumptions about the (potential) biodiversity benefits of using these broadly defined land uses (Felton et al., 2010; Dauber et al., 2012). A clear distinction between degraded, marginal or low-intensity pasture or grassland is often lacking, whereas at the same time such areas might hold 
important biodiversity values. Various studies have shown that conversion of such lands into plantations of perennial crops may therefore also result in negative impacts on biodiversity (e.g., Felton et al., 2010; Fletcher et al., 2010; Hsu et al., 2010; van der Hilst et al., 2012).

\section{Different crops have different impacts}

The impacts of second generation crops tend to be less negative than first generation ones, and are in several cases positive (at the field scale). About $87 \%$ of the studies on first generation crops report negative impacts, vs. $27 \%$ for second generation crops. Positive effects are shown in $32 \%$ of these studies, and are especially true for grasses and SRC crops in Europe. The reported impacts per bioenergy crop are presented in Fig. 6 .

A total of 20 studies report both positive and negative (or neutral) impacts, the majority for second generation crops. In some cases (five), combined analyses of first and second generation crops showed negative impacts on the first, and positive effects on the latter. Perennial crops have the potential to provide habitat or shelter for specific species (such as migratory birds) and improve connectivity or support restoration of degraded or marginal land, resulting in biodiversity benefits (Dauber et al., 2010; Meehan et al., 2010; Robertson et al., 2011a). These studies are, however, cautious in presenting positive results on second generation crops and indicate that biodiversity benefits depend on (1) different species responses within and between taxonomic groups, (2) different spatial scales at which studies are conducted, and (3) management, age, size and heterogeneity of plantations. This also relates to the increased vulnerability of an area to new invasive species when landscape heterogeneity is reduced (Hartman et al., 2011). Similar conclusions are drawn by other reviews on forest plantations (e.g., Brockerhoff et al., 2008; Schulz et al., 2009). An additional notion here is that except for one scenario-based assessment in Argentina (van Dam et al., 2009), none of the studies evaluate the (potential) impacts from second generation feedstock cultivation in tropical regions.

The large share of studies focused on second generation crops in temperate regions and oil palm in Indonesia and Malaysia, shows important gaps in knowledge particularly in tropical regions. Although a significant proportion of first-generation biofuel feedstocks are produced in the tropics and the demand for these crops are likely to continue at least in the next decade, quantified results are largely biased towards oil palm in South East Asia (Lee et al., 2011). Continued production of bioenergy crops in the tropics is expected to (further) threaten the high concentrations of globally endemic species in these areas, which are located within the world's key biodiversity hotspots such as the Brazilian Cerrado (Myers et al., 2000; Klink \& Machado, 2005; Koh \& Ghazoul, 2008; Sano et al., 2010). These regions are still relatively unexplored in bioenergy science, whereas uncertainties are likely to be larger (due to, for example, higher levels of endemism as well as lack of data).

\section{Evidence of quantified impacts using different biodiversity indicators}

No single indicator covers the totality of the various impacts on biodiversity; consequently the evidence of quantified biodiversity impacts in this review is based on different biodiversity indicators. The main indicators

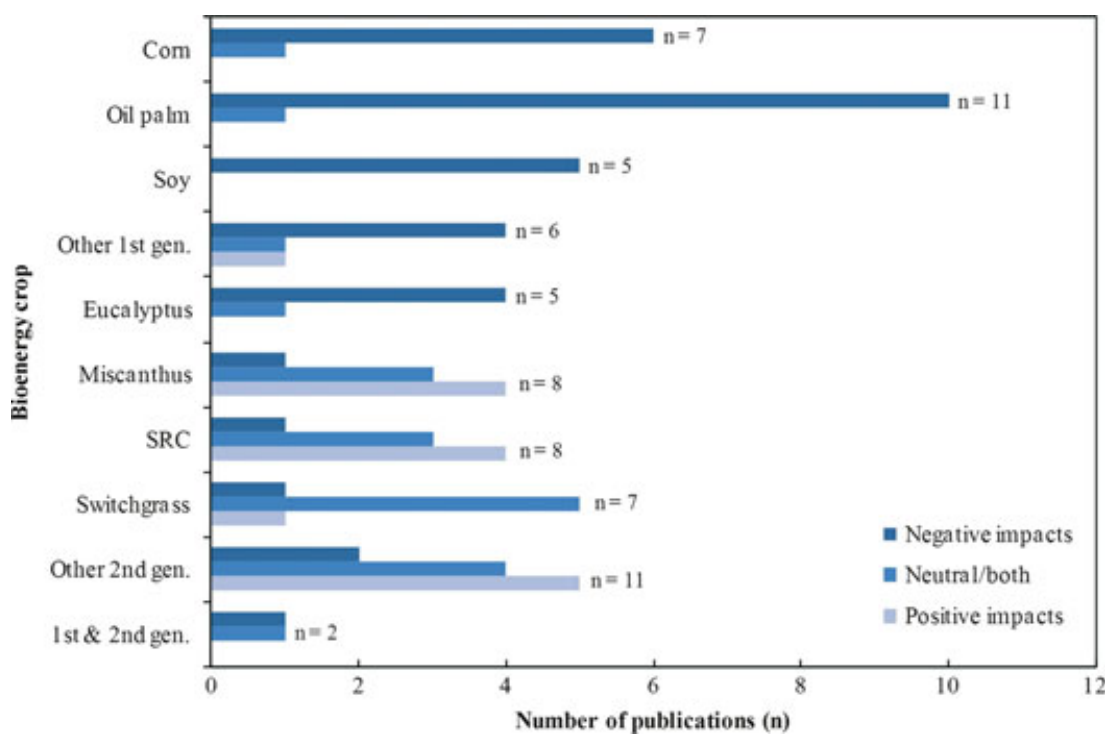

Fig. 6 Biodiversity impacts per bioenergy crop. 


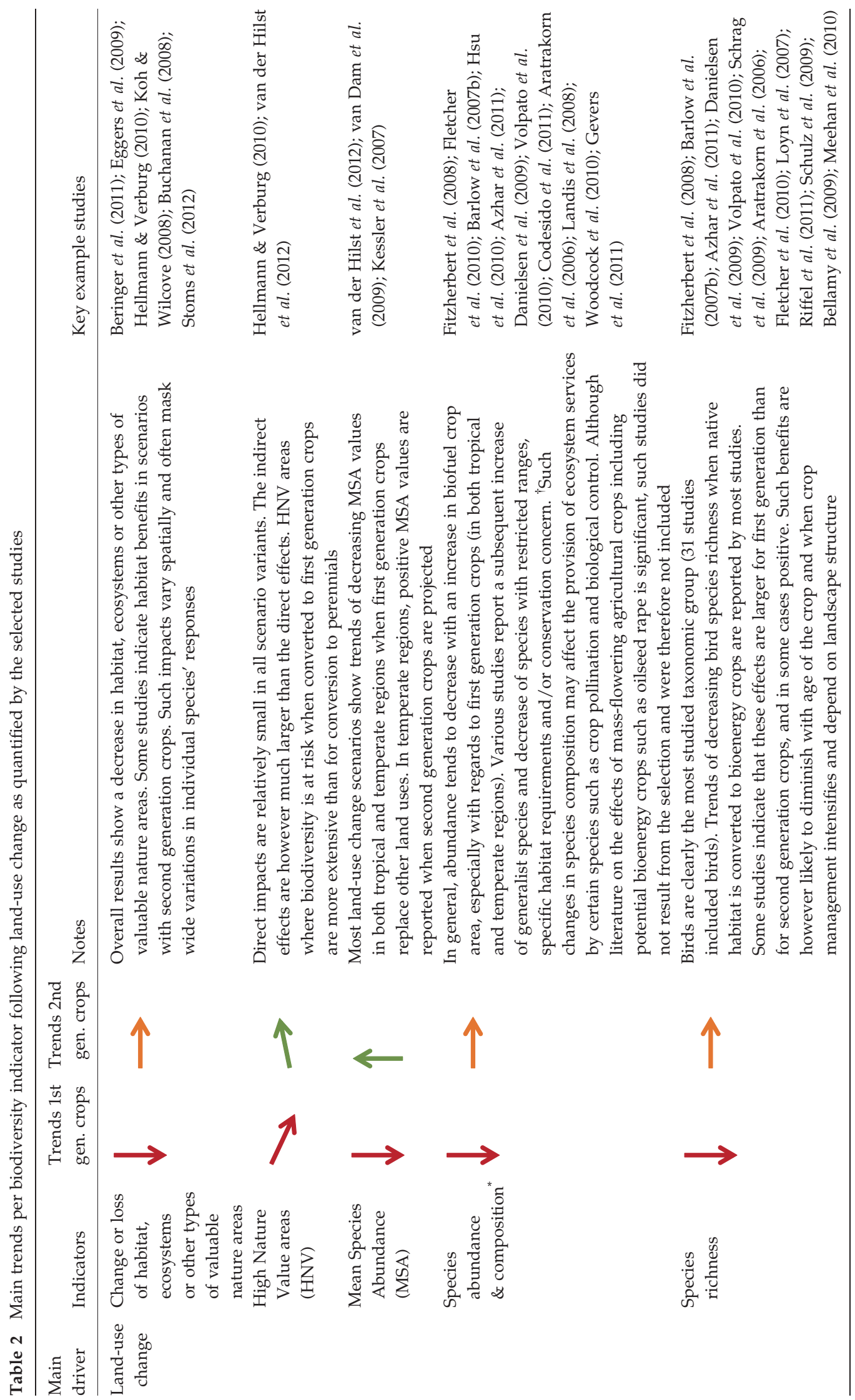




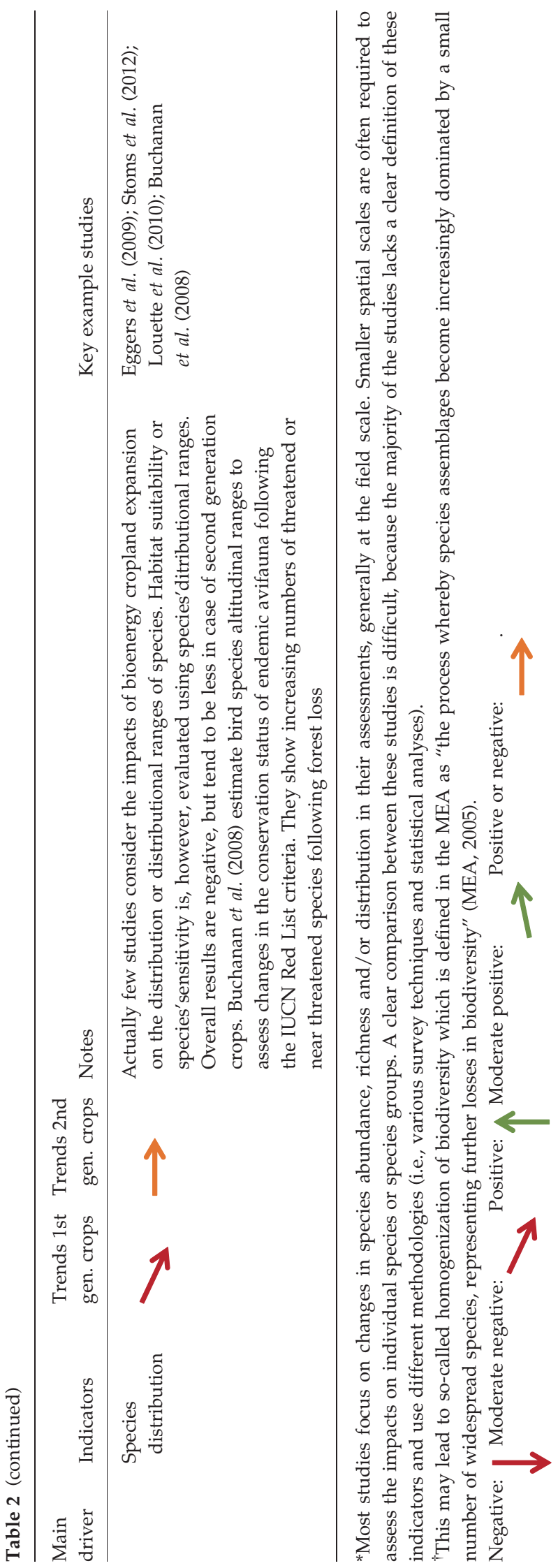

used in the selected studies are (1) change or loss of habitat, ecosystems or other types of valuable nature areas, (2) High Nature Value areas (HNV), (3) Mean Species Abundance (MSA) and (4) indices for species abundance, richness and distribution. Definitions of these indicators are presented in Appendix S1. Table 2 explains the main trends per biodiversity indicator, and indicates key example studies. The results are shown following the quantified effects of land-use change, being the focus of the majority of the studies.

\section{Conditions under which biodiversity indicators are applied}

Table 3 summarizes the conditions under which the main biodiversity indicators are applied in the selected publications including spatial scale, biodiversity level, time horizon and data requirements.

The extent of habitat, ecosystems or other types of valuable nature areas is a widely used indicator for biodiversity on each spatial scale, especially in areas outside agricultural lands. Data are readily available (often from satellite images) and can be applied in both empirical and scenario-based assessments. Data are frequently on a coarse scale and would therefore require field verification to improve the accuracy of mapping exercises. Assessments of the impacts on individual species or species groups are difficult solemnly using this type of indicator. Indicators that can be applied to include changes within or between species (groups) at larger spatial scales are the HNV and MSA. The HNV indicator is currently only available for Europe and would require large amounts of data in other regions. This makes it difficult to apply this indicator in (scenariobased) assessments outside Europe. Besides, there are still important challenges in using the HNV indicator in Europe especially due to differences and limitations in data and methodologies (Peppiette, 2011).

The MSA is a less precise, but relatively easily applicable indicator that can provide an indication of (potential) changes in the relative abundance of species, also in future scenarios. It is, however, difficult to apply the indicator at smaller spatial scales because of the low level of detail and considerable uncertainties related to the cause-effect relationships, the drivers considered and underlying data determining the MSA values. Assessments of species distribution can provide more species-specific information at larger spatial scales and can be applied together with indices for species richness and abundance in impact assessments at smaller spatial scales. These indicators allow for analysis of changes in individual species or species groups in both natural areas and agricultural landscapes and provide more accurate information at the species level. The use of these indicators is, however, data intensive and often 
202 D. J. IMMERZEEL et al.

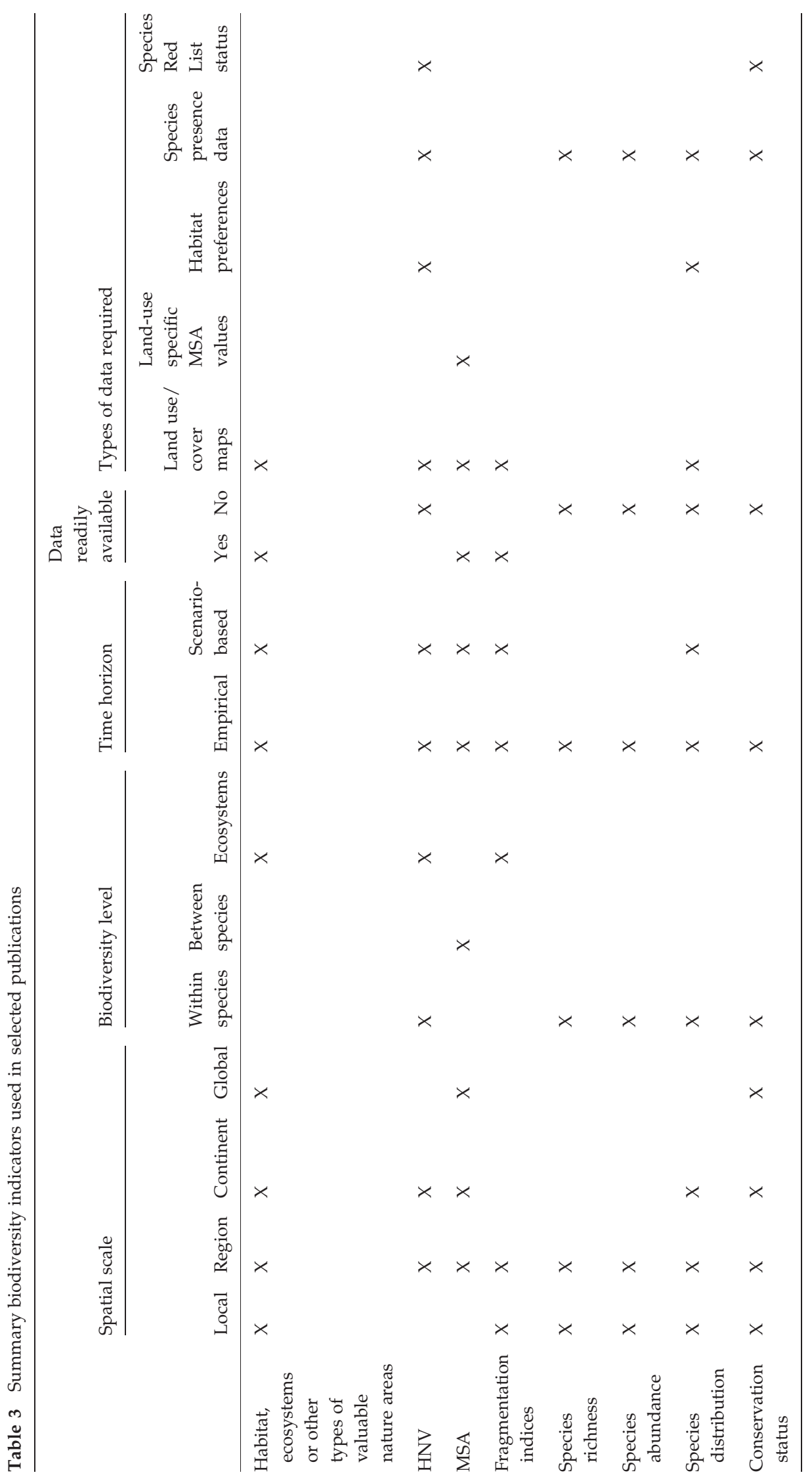

C 2013 Blackwell Publishing Ltd, GCB Bioenergy, 6, 183-209 
requires long-term field surveys. Besides, they are difficult to apply in scenario-based assessments as changes in these indicators are hard to project.

Fragmentation indices can add an extra dimension to the above indicators and can provide insight into the effects of fragment size and landscape connectivity on biodiversity, especially if such indices can be related to species-specific indicators at smaller spatial scales. Fragmentation indices can be relatively easily calculated from land use and land cover data. An analysis of the relationship between fragmentation and species-specific indicators requires, however, more data intensive research. Few selected studies have directly referred to or assessed the integrated effects of fragmentation. Fragmentation effects are defined by Fahrig (2003) and include (1) reduction in habitat amount, (2) increase in the number of habitat patches, (3) decrease in sizes of habitat patches and (4) increase in isolation of patches. Added to this can be so-called edge effects, where the area of land at the edge of the habitat patch is altered and less suitable for certain species (MEA, 2005; Verweij et al., 2009). Species that are specialized to particular habitats and those with poor dispersal ability suffer from fragmentation more than generalist species with good dispersal ability. This may affect the extinction risk of the more vulnerable species. Habitat loss and such changes in species composition are addressed by the selected studies, but most authors do not distinguish between habitat loss and habitat fragmentation or consider fragmentation related habitat variables at the field scale, not at the landscape scale [as was also concluded by Fahrig (2003)]. Only one study showed that oil palm is a major contributor to forest fragmentation using a fragmentation index (Abdullah \& Nakagoshi, 2007).

Changes in the conservation status of species are also scarcely included in bioenergy literature. At smaller spatial scales, changes in the conservation status are difficult to assess, but at larger spatial scales an increased number of for example vulnerable or (critically) endangered species can provide an important proxy for changes in the state of biodiversity.

Insights from several reviews of biodiversity indicators show that the selected publications exclude several indicators that are often used in biodiversity research (e.g., Reid et al., 1993; Brink, 2000; Dornburg et al., 2008; Butchart et al., 2010; Vačkář et al., 2012). These indicators include, for example, the extent of protected areas, Red List Index and Living Planet Index (LPI). An explanation of these indicators is included in Appendix S1.

\section{Responses}

This review shows that bioenergy crop production leads to various tradeoffs on biodiversity. Reconciling biofuel expansion with biodiversity conservation is therefore not easy (Dornburg et al., 2010; Lee et al., 2011). To mitigate the negative impacts of biofuel feedstock cultivation on biodiversity and to promote biodiversity benefits, various measures are proposed and discussed in literature. These mitigating measures are not focused on the bioenergy sector alone, but should be seen in the context of other associated land uses. As also indicated by Wicke et al. (2012), mitigating the impacts of bioenergy crop production, either directly or indirectly, depends on controlling the extent of land-use changes related to biofuel feedstock expansion, including, for example, forestry, agriculture and livestock sectors. Here, these measures are shortly discussed based on the selected publications, and complemented with additional key references.

\section{Better management practices}

The implementation of better management practices can contribute to the enhancement of (agro)biodiversity at the field scale as well as landscape heterogeneity. Such practices have been proposed by many and include crop rotations or multiple cropping systems, use of native species and local varieties, enhancement of understory vegetation, no till farming, minimal irrigation and responsible use of pesticides and fertilizers (e.g., Hennenberg et al., 2010; Nájera, 2010; Lee et al., 2011; Wiens et al., 2011; Calviño-Cancela et al., 2012; Wicke et al., 2012). Increased structural diversity and maintenance or creation of landscape elements within plantations can contribute to landscape heterogeneity. Such elements can contribute to connectivity and reduce fragmentation effects and include, for example, stepping stones of natural habitats, buffer zones around vulnerable areas, protection of riparian areas, slopes and other fragile areas (Fletcher et al., 2010; Hennenberg et al., 2010; Hartman et al., 2011). Improvement of structural diversity might also contribute to limiting the risk of invasion by perennial grasses. Finally, various studies propose a precautionary approach when introducing potentially invasive biofuel feedstocks through pre-introduction screening or risk assessments (e.g., Barney \& Ditomaso, 2008; Gordon et al., 2011).

\section{Use of marginal, degraded or abandoned agricultural land}

As discussed before, the use of marginal, degraded or abandoned is often promoted as an option to minimize competition with food crops and reduce the need for conversion of natural ecosystems (e.g., Fitzherbert et al., 2008; van Dam et al., 2009; Hartman et al., 2011). Feedstock cultivation on such lands may also provide additional environmental benefits such as erosion control 
and soil carbon sequestration (Hartman et al., 2011; Wicke et al., 2012). Key uncertainties exist, however, in relation to the definition and identification of such lands, potential yields and their biodiversity and socioeconomic values (Dauber et al., 2012; Wicke et al., 2012; see previous sections). Dauber et al. (2012) provide a recent scientific background in support of a reassessment of land available for bioenergy production by clarifying the terminology, identifying constraints and options for efficient bioenergy-use of surplus land.

\section{Land-use planning and landscape design}

Conservation gains from avoiding or reducing deforestation of natural or high biodiversity value areas, can only be achieved in combination with land-use planning and landscape design (Fitzherbert et al., 2008). As indicated by Wicke et al.(2012), appropriate zoning of land use and land cover is necessary to minimize negative impacts from land-use changes associated to bioenergy cropland expansion. Various authors indicate the importance of maintaining or enhancing heterogeneity in the landscape (e.g., Hsu et al., 2010; Azhar et al., 2011; Hartman et al., 2011; Baum et al., 2012). This can be performed through the retention and restoration of natural forest or other areas of natural vegetation outside plantations (Azhar et al., 2011). Agroforestry or silvopastoral production systems may also act as corridors to connect surrounding fragments, but also to mitigate further encroachment into these areas and reduce edge effects (Lee et al., 2011; Holzmeuller \& Jose, 2012; Wicke et al., 2012). Others point towards combined food and energy (CFE) agro-ecosystems that can provide significantly increased ecosystem services compared with conventional agriculture and require less fossil-based inputs (Porter et al., 2009). Besides, biofuel crops have the potential to stimulate landscape heterogeneity themselves by introducing perennial energy crops into landscapes dominated by annual crops (Wiens et al., 2011). Care should, however, be taken here considering the land-use type that is being replaced (see previous sections and e.g., Dauber et al., 2012).

\section{Policy and regulatory measures}

As the most serious impacts on biodiversity result from the conversion of natural vegetation to bioenergy crop plantations, major gains in conserving biodiversity can be achieved by implementing measures aimed at the conservation or exclusion of natural habitats, ecosystems or other areas with high-nature values. These can include not only primary forests but also, for example, valuable secondary forests, natural grasslands and peat lands (e.g., Koh \& Wilcove, 2008). Such policy and regulatory measures include the establishment of new protected areas, improvement of protected area networks through, for example, buffer zones and ecological corridors as well as the enhancement of regulation and enforcement to limit deforestation. At the same time, these measures might be most challenging, especially in tropical countries where law enforcement is often weak. Besides, the identification of areas with high-nature values still faces methodological challenges (see Appendix S1).

\section{(Voluntary) certification initiatives}

Over the years, a wide range of certification initiatives has started aimed at the development of sustainability standards for bioenergy production and trade. The creation of multi stakeholder initiatives such as the Roundtable of Sustainable Biofuels, the Roundtable of Responsible Soy, Bonsucro and the Roundtable of Sustainable Palm Oil have engaged stakeholders throughout the entire supply chain to work towards the production and trade of bioenergy feedstocks following sets of economic, social and environmental criteria (Lee et al., 2011). Research on the effects of certification on biodiversity is still limited, which makes it difficult to draw conclusions on this issue. Besides, various studies indicate that current initiatives still fail to capture iLUC (e.g., van Dam et al., 2010; Hennenberg et al., 2010; Lee et al., 2011). Most bioenergy sustainability criteria deal with biodiversity by proposing process indicators, for example, by referring to national regulations and by excluding protected areas and land identified as HCVA from bioenergy production. However, none of the current systems is built on a coherent and proven set of methodologies that allows for trustworthy verification of criteria and indicators (van Dam et al., 2008). Following the above challenges, various authors argue that certification systems should be complemented by science-based methodologies and additional mitigating measures at multiple spatial scales (e.g., van Dam et al., 2010; Hennenberg et al., 2010).

\section{Mitigating measures not addressed in the selected studies}

The selected studies address to a limited extent the importance of good governance in establishing an enabling environment for the implementation of mitigating measures. Policy frameworks at national and international levels (such as the EU Renewable Energy Directive) can contribute to stimulating sustainable bioenergy supply chains, although it is important that policies in various sectors (including e.g., agriculture, environment and rural development) are aligned. Other (financial) incentives to alleviate the pressure from 
bioenergy crop production on natural ecosystems that have hardly been addressed include the creation of innovative financing mechanisms such as Payments for Environmental Services. To be effective, however, financing schemes must provide an economically (and socially) attractive alternative production system and fulfil several key requirements to prevent negative consequences such as leakage in other areas (Wunder et al., 2008). Finally, partnerships between multiple stakeholders could fill the gap in these and other mitigating measures where there is a lack of regulations, law enforcement or land-use planning policy by governments for example (Visseren-Hamakers \& Glasbergen, 2007; Fitzherbert et al., 2008; Lee et al., 2011).

\section{Conclusions and recommendations for future research}

This article comprehensively and systematically reviewed publications on the biodiversity impacts of bioenergy crop production. The article evaluated the drivers and pressures of biodiversity change and summarized current trends and impacts. The review provided insight into the types of biodiversity indicators applied under a range of conditions and the mitigating measures proposed to minimize negative impacts or realize biodiversity benefits. The selection of publications is not considered exhaustive. The selection of 53 studies resulted from the applied search method, whereas other combinations of search terms and/or search engines might have resulted in additional studies. Nonetheless, this article presented a state-of-the-art review of biodiversity impacts in literature on bioenergy crop production, identifying important knowledge gaps in this field of science.

The selected publications gave diverse results that were difficult to compare. Clear definitions on drivers, pressures and impacts on biodiversity, and even of biodiversity itself, are often lacking in current literature. The use of the DPSIR framework enabled, however, a structured analysis of the wide ranging publications. The differences were explained by the various spatial scales, production systems and regions, time horizons, methodologies and biodiversity indicators used. Most studies focus on the field level. Reported impacts depend on initial land use and are mostly negative, in particular in tropical regions. The impacts of second generation bioenergy crops tend to be less negative than first generation ones, and are in some cases positive (at the field level), in particular in temperate regions. Landuse change appears as the key driver of biodiversity change, whereas the associated habitat loss, alterations in species richness and abundance are the main impacts addressed. Such changes are often paired with the (initiation of a) process of biological homogenization. The article confirms that concerns about the expansion of bioenergy crop production not only relate to direct land-use change effects on biodiversity by replacing natural vegetation, but increasingly to the indirect effects as well. These effects have, however, shown to be difficult to quantify. At the same time, the land sparing vs. land sharing debate receives growing attention whereas little evidence exists in bioenergy literature on the impacts of large-scale application of these strategies on (agro) biodiversity. Finally, several mitigating measures were identified in bioenergy literature to minimize negative impacts or enhance biodiversity benefits. These measures included better management practices, the use of degraded lands, land-use planning and landscape design, policy and regulatory measures as well as other initiatives promoting a more sustainable bioenergy sector.

This review showed important gaps in knowledge on bioenergy crop production, which are translated here into recommendations for future research. These recommendations are considered essential for the guidance and development of mitigating measures and include the following:

- Diversification of study regions and target crops to other 'conversion hotspots' in biodiversity rich tropical ecosystems including, for example, the Cerrado, Atlantic Forest and Chaco in South America, as well as wetlands and other vulnerable arid and semi-arid ecosystems in sub-Saharan Africa.

- Integration of multiple spatial scales to avoid the current bias towards the field scale and expand the knowledge at larger spatial scales. This requires the use of coarser indicators that can be applied at such spatial scales including, for example, the extent of ecosystems and the MSA, but also indicators that are currently not represented in bioenergy literature such as the Red List Index (RLI). On these coarser spatial scales, this requires modelling approaches on biodiversity responses that are based on accurate projections of future distributions of energy crops. Such projections are, however, challenged by, for example, the time lags of biodiversity responses and low current acreage providing limited baseline information, particularly in case of second generation crops.

- The complexity of biodiversity requires a combination of complementary indicators on different biodiversity levels. Combinations of various indices are recommended to cover a broader range of the status, trends and changes in biodiversity and the ecosystem services provided by biodiversity (this follows the recommendations of the CBD 
(CBD, 2010)). For example, the use of habitat, ecosystems or other types of valuable nature areas neglects biodiversity outside these areas. The MSA indicator can then provide complementary information in scenario-based assessments at larger spatial scales. To include more species-specific data, the use of species distribution data can complement the MSA especially on larger spatial scales. To further overcome the limitations of the MSA at smaller spatial scales, indices for species richness and abundance can be applied in impact assessments of changes in biodiversity in both natural areas and agricultural landscapes. The most suitable set of applicable indicators depends, however, on the purpose of the study and data and time availability.

- Improved insights into changes in species distribution resulting from bioenergy crop production as currently little is known regarding such changes. This can support land-use planning initiatives by identifying, for example, priority areas for conservation that are important in maintaining species' distributional ranges and capacity.

- Broadening of taxonomic groups to better evaluate differences in responses to bioenergy crop expansion between taxonomic groups. Selecting indicator species (groups) for biodiversity is a challenge, as the findings about the usefulness of certain species groups as indicators are contradictory (Lindenmayer et al., 2000; Dauber et al., 2010). Therefore a broader perspective on how different taxonomic groups are affected can improve the understanding of biodiversity impacts at the species level.

- Assessments of changes in species extinction risk in response to bioenergy crop expansion can further guide conservation actions and can be an important tool in selecting indicator species for impacts assessments. Depending on the spatial scale, this can include assessments using the RLI or evaluations of changes in the conservation status of particular species.

- Quantification of pollution effects on biodiversity from the use of fertilizers, pesticides and discharge of waste, especially in aquatic ecosystems. Impact assessments are concentrated on terrestrial ecosystems, partly due to a lack of data on biodiversity in aquatic ecosystems. Increasing concerns have risen on these ecosystems; however, also in the context of bioenergy crop production (where upstream and downstream impacts are often not taken into account).

- Relating climate change effects from biomass production to biodiversity. One of the main arguments for biomass production for bioenergy is its potential contribution to the reduction in GHG emissions. Global and regional studies indicate possible negative impacts of climate change on biodiversity; therefore insights into the long-term climate change effects from biomass production on biodiversity could assist in minimizing these negative climate change impacts.

- Studies on the effects of mitigating measures on biodiversity to improve or further guide such measures.

- This should include specific attention to a better understanding of the effects of intensification of production systems on (agro)biodiversity. When mitigating measures with respect to biodiversity are primarily focused at the conservation of natural areas (as is the basis of most sustainability initiatives), such measures should be complemented with management practices to improve production efficiency and reduce the need for expansion elsewhere. Large uncertainties remain, however, regarding the effects of these 'land sparing' options, especially with regards to availability and suitability of land. Assessments of this type of strategy should not only include landscape level effects of intensification on habitat extent, landscape connectivity and fragmentation, but also species-specific indicators such as richness and abundance at the field scale.

- On the other hand, 'land sharing' options via alternative cropping systems such as agroforestry should become research priority. Positive biodiversity impacts from biodiversity friendly cropping systems are presented in literature, but also here large uncertainties remain. A stronger scientific basis in this debate would allow for better (regional) solutions to establish more sustainable bioenergy production systems with optimized production (Dauber et al., 2012).

- Apart from quantifying impacts from different production systems, detailed assessment and definition of the potential of marginal and degraded land are needed. This calls for a thorough analysis of the state of biodiversity in such areas using more precise and species-specific indicators for species richness, abundance and distribution to capture the full value of these areas and identify under which conditions these areas can be optimally used for bioenergy crop production.

- Long-term studies are, however, needed to realize most of the above recommendations. Field-based data are often collected within a relatively short time frame covering several years or a decade at the most. Scenario-based assessments project larger time frame of several decades, but have to be based on a wide range of general assumptions. Accurate biodiversity impact assessments require long-term 
studies to understand the multiple drivers of biodiversity change and their associated impacts.

\section{Acknowledgements}

This work was carried out within the BE-Basic R\&D Program, which was granted a FES subsidy from the Dutch Ministry of Economic Affairs, Agriculture and Innovation (EL\&I) (http:// www.be-basic.org).

\section{References}

Abdullah SA, Nakagoshi N (2007) Forest fragmentation and its correlation to human land use change in the state of Selangor, peninsular Malaysia. Forest Ecology and Management, 241, 39-48.

Anderson-Teixeira KJ, Duval BD, Long SP, DeLucia EH (2012) Biofuels on the landscape, is "land sharing" preferable to "land sparing"? Ecological Applications, 22, 2035-2048.

Aratrakorn S, Thunhikorn S, Donald PF (2006) Changes in bird communities following conversion of lowland forest to oil palm and rubber plantations in southern Thailand. Bird Conservation International, 16, 71-82.

Azhar B, Lindenmayer DB, Wood J, Fischer J, Manning A, McElhinny C, Zakaria M (2011) The conservation value of oil palm plantation estates, smallholdings and logged peat swamp forest for birds. Forest Ecology and Management, 262, 2306-2315.

Barlow J, Gardner TA, Araujo IS et al. (2007a) Quantifying the biodiversity value of tropical primary, secondary, and plantation forests. Proceedings of the National Academy of Sciences, 104, 18555-18560.

Barlow J, Mestre LAM, Gardner TA, Peres CA (2007b) The value of primary, secondary and plantation forests for Amazonian birds. Biological Conservation, 136, 212-231.

Barney JN, Ditomaso JM (2008) Nonnative species and bioenergy, Are we cultivating the next invader? BioScience, 58, 64-70.

Barney JN, Mann JJ, Kyser GB, Ditomaso JM (2012) Assessing habitat susceptibility and resistance to invasion by the bioenergy crops switchgrass and Miscanthus $\times$ giganteus in California. Biomass and Bioenergy, 40, 143-154.

Baum S, Bolte A, Weih M (2012) Short rotation coppice (SRC) plantations provide additional habitats for vascular plant species in agricultural mosaic landscapes. BioEnergy Research, 5, 1-11.

Bellamy PE, Croxton PJ, Heard MS et al. (2009) The impact of growing miscanthus for biomass on farmland bird populations. Biomass and Bioenergy, 33, 191-199.

Beringer TIM, Lucht W, Schaphoff S (2011) Bioenergy production potential of global biomass plantations under environmental and agricultural constraints. Global Change Biology Bioenergy, 3, 299-312.

Berndt AM, Hölzel N (2012) Energy crops as a new bird habitat, Utilization of oilseed rape fields by the rare blue throat (luscinia svecica). Biodiversity and Conservation, 21, 1-15.

ten Brink B (2000) Biodiversity Indicators for the OECD Environmental Outlook and Strategy - A Feasibility Study. National Institute of Public Health and the Environment (RIVM), Bilthoven, The Netherlands.

ten Brink BB, Alkemade R, Bakkenes M et al. (2007) Cross-Roads of Life on Earth Exploring Means to Meet the 2010 Biodiversity Target. Solution Oriented Scenarios for Global Biodiversity Outlook 2. Technical series no. 31. Secretariat of the Convention on Biological Diversity, Montreal, Canada.

Brockerhoff EG, Jactel H, Parrotta JA, Quine CP, Sayer J (2008) Plantation forests and biodiversity, Oxymoron or opportunity? Biodiversity and Conservation, 17, 925-951.

Brühl CA, Eltz T (2010) Fuelling the biodiversity crisis, species loss of ground-dwelling forest ants in oil palm plantations in Sabah, Malaysia (Borneo). Biodiversity and Conservation, 19, 519-529.

Buchanan GM, Butchart SHM, Dutson G, Pilgrim JD, Steininger MK, Bishop KD, Mayaux P (2008) Using remote sensing to inform conservation status assessment, estimates of recent deforestation rates on New Britain and the impacts upon endemic birds. Biological Conservation, 141, 56-66.

Butchart SHM, Walpole M, Collen B et al. (2010) Global biodiversity, indicators of recent declines. Science, 328, 1164-1168.

Calviño-Cancela M, Rubido-Bará M, van Etten EJB (2012) Do eucalypt plantations provide habitat for native forest biodiversity? Forest Ecology and Management, 270, $153-162$
CBD (2010) Global Biodiversity Outlook 3. Secretariat of the Convention on Biological Diversity (CBD), Montréal, Canada.

Chum H, Faaij APC, Moreira J et al. (2011) 2011, Bioenergy. In: IPCC Special Report on Renewable Energy Sources and Climate Change Mitigation (eds Edenhofer $\mathrm{O}$, Pichs-Madruga R, Sokona Y, Seyboth K, Matschoss P, Kadner S, Zwickel T, Eickemeier P, Hansen G, Schlömer S, von Stechow C, pp. 209-332. Cambridge University Press, Cambridge, United Kingdom and New York, USA.

Codesido M, Gonzalez-Fischer C, Bilenca D (2011) Distributional changes of landbird species in agroecosystems of central Argentina. Condor, 113, 266-273.

van Dam J, Junginger M, Faaij APC, Jürgens I, Best G, Fritsche U (2008) Overview of recent developments in sustainable biomass certification. Biomass and Bioenergy, 32, 749-780.

van Dam J, Faaij APC, Hilbert J, Petruzzi H, Turkenburg WC (2009) Large-scale bioenergy production from soybeans and switchgrass in Argentina. Part B. environmental and socio-economic impacts on a regional level. Renewable and Sustainable Energy Reviews, 13, 1679-1709.

van Dam J, Junginger M, Faaij APC (2010) From the global efforts on certification of bioenergy towards an integrated approach based on sustainable land use planning. Renewable and Sustainable Energy Reviews, 14, 2445-2472.

Danielsen F, Beukema H, Burgess ND et al. (2009) Biofuel plantations on forested lands, Double jeopardy for biodiversity and climate. Conservation Biology, 23, 348-358.

Dauber J, Jones MB, Stout JC (2010) The impact of biomass crop cultivation on temperate biodiversity. Global Change Biology Bioenergy, 2, 289-309.

Dauber J, Brown C, Fernando AL et al. (2012) Bioenergy from "surplus" land, environmental and socio-economic implications. BioRisk, 7, 5-50.

Dhondt AA, Wrege PH, Cerretani J, Sydenstricker KV (2007) Avian species richness and reproduction in short-rotation coppice habitats in central and western New York, Capsule species richness and density increase rapidly with coppice age, and are similar to estimates from early successional habitats. Bird Study, 54, $12-22$.

Dornburg V, Faaij APC, Verweij PA et al. (2008) Climate Change Scientific Assessment and Policy Analysis. Biomass Assessment - Assessment of Global Biomass Potentials and Their Links to Food, Water, Biodiversity, Energy Demand and Economy, Inventory and Analysis of Existing Studies. Performed within the framework of the Netherlands Research Programme on Scientific Assessment and Policy Analysis for Climate Change (WAB). Netherlands Environmental Assessment Agency (MNP), Bilthoven, The Netherlands.

Dornburg V, van Vuuren D, van de Ven G et al. (2010) Bioenergy revisited, key factors in global potentials of bioenergy. Energy and Environmental Science, 3, 258-267.

Eggers J, Tröltzsch K, Falucci A et al. (2009) Is biofuel policy harming biodiversity in Europe? Global Change Biology Bioenergy, 1, 18-34.

Fahrig L (2003) Effects of habitat fragmentation on biodiversity. Annual Review of Ecology, Evolution, and Systematics, 34, 487-515.

Fayle TM, Turner EC, Snaddon JL, Chey VK, Chung AYC, Eggleton P, Foster WA (2010) Oil palm expansion into rain forest greatly reduces ant biodiversity in canopy, epiphytes and leaf-litter. Basic and Applied Ecology, 11, 337-345.

Felten D, Emmerling C (2011) Effects of bioenergy crop cultivation on earthworm communities - a comparative study of perennial (miscanthus) and annual crops with consideration of graded land-use intensity. Applied Soil Ecology, 49, 167-177.

Felton A, Knight E, Wood J, Zammit C, Lindenmayer D (2010) A meta-analysis of fauna and flora species richness and abundance in plantations and pasture lands. Biological Conservation, 143, 545-554.

Fischer J, Brosi B, Daily GC et al. (2008) Should agricultural policies encourage land sparing or wildlife-friendly farming? Frontiers in Ecology and the Environment, 6, 380-385.

Fitzherbert EB, Struebig MJ, Morel A, Danielsen F, Brühl CA, Donald PF, Phalan B (2008) How will oil palm expansion affect biodiversity? Trends in Ecology \& Evolution, 23, 538-545.

Fletcher RJ Jr, Robertson BA, Evans L, Doran PJ, Alavalapati JRR, Schemske DW (2010) Biodiversity conservation in the era of biofuels, Risks and opportunities. Frontiers in Ecology and the Environment, 3, 161-168.

Gasparatos A, Stromberg P, Takeuchi K (2011) Biofuels, ecosystem services and human wellbeing, Putting biofuels in the ecosystem services narrative. Agriculture, Ecosystems \& Environment, 142, 111-128.

Gevers J, Hoye TT, Topping CJ, Glemnitz M, Schroeder B (2011) Biodiversity and the mitigation of climate change through bioenergy, impacts of increased maize cultivation on farmland wildlife. Global Change Biology Bioenergy, 3, $472-482$. 
Gordon DR, Tancig KJ, Onderdonk DA, Gantz CA (2011) Assessing the invasive potential of biofuel species proposed for Florida and the United States using the Australian weed risk assessment. Biomass and Bioenergy, 35, 74-79.

Haberl H, Gaube V, Díaz-Delgado R et al. (2009) Towards an integrated model of socioeconomic biodiversity drivers, pressures and impacts. A feasibility study based on three European long-term socio-ecological research platforms. Ecological Economics, 68, 1797-1812

Hartman JC, Nippert JB, Orozco RA, Springer CJ (2011) Potential ecological impacts of switchgrass (panicum virgatum $\mathrm{L}$.) biofuel cultivation in the central great plains, USA. Biomass and Bioenergy, 35, 3415-3421.

Haughton AJ, Bond AJ, Lovett AA et al. (2009) A novel, integrated approach to assessing social, economic and environmental implications of changing rural land-use, a case study of perennial biomass crops. Journal of Applied Ecology, 46, 315-322.

Hellmann F, Verburg PH (2010) Impact assessment of the European biofuel directive on land use and biodiversity. Journal of Environmental Management, 91, 1389-1396.

Hennenberg KJ, Dragisic C, Haye S et al. (2010) The power of bioenergy-related standards to protect biodiversity. Conservation Biology, 24, 412-423.

van der Hilst F, Lesschen JP, van Dam JMC, Riksen M, Verweij PA, Sanders JPM, Faaij APC (2012) Spatial variation of environmental impacts of regional biomass chains. Renewable and Sustainable Energy Reviews, 16, 2053-2069.

van der Hilst F, Verstegen JA, Zheliezna T, Drozdova O, Faaij APC (Forthcoming) Integrated spatiotemporal analysis of agricultural land use, bioenergy production potentials and related GHG balances in Ukraine.

Holzmeuller EJ, Jose S (2012) Biomass production for biofuels using agroforestry, potential for the North Central Region of the United States. Agroforestry Systems, 85, 305-314.

Hsu T, French K, Major R (2010) Avian assemblages in eucalypt forests, plantations and pastures in northern NSW, Australia. Forest Ecology and Management, 260, 1036-1046.

Jackson LE, Pascual U, Hodgkin T (2007) Utilizing and conserving agrobiodiversity in agricultural landscapes. Agriculture, Ecosystems \& Environment, 121, 196-210.

Kessler JJ, Rood T, Tekelenburg T, Bakkenes M (2007) Biodiversity and socioeconomic impacts of selected agro-commodity production systems. Journal of Environment and Development, 16, 131-160.

Klink CA, Machado RB (2005) Conservation of the Brazilian Cerrado. Conservation Biology, 19, 707-713.

Koh LP, Ghazoul J (2008) Biofuels, biodiversity, and people, understanding the conflicts and finding opportunities. Biological Conservation, 141, 2450-2460.

Koh LP, Wilcove DS (2008) Is oil palm agriculture really destroying tropical biodiversity? Conservation Letters, 1, 60-64.

Landis DA, Gardiner MM, van der Werf W, Swinton SM (2008) Increasing corn for biofuel production reduces biocontrol services in agricultural landscapes. Proceedings of the National Academy of Sciences, 105, 20552-20557.

Lee JSH, Garcia-Ulloa J, Koh LP (2011) Impacts of biofuel expansion in biodiversity hotspots. Biodiversity Hotspots, 277-293.

Lindenmayer DB, Margules CR, Botkin DB (2000) Indicators of biodiversity for ecologically sustainable forest management. Conservation Biology, 14, 941-950.

Louette G, Maes D, Alkemade R et al. (2010) BioScore-cost-effective assessment of policy impact on biodiversity using species sensitivity scores. Journal for Nature Conservation, 18, 142-148.

Loyn RH, McNabb EG, Macak P, Noble P (2007) Eucalypt plantations as habitat for birds on previously cleared farmland in south-eastern Australia. Biological Conservation, $137,533-548$

Maxim L, Spangenberg JH, O'Connor M (2009) An analysis of risks for biodiversity under the DPSIR framework. Ecological Economics, 69, 12-23.

MEA (2005) Ecosystems and Human Well-Being, Synthesis of the Millennium Ecosystem Assessment. Island Press, Washington, D.C., USA.

Meehan TD, Hurlbert AH, Gratton C (2010) Bird communities in future bioenergy landscapes of the upper Midwest. Proceedings of the National Academy of Sciences of the United States of America, 107, 18533-18538.

Morton DC, DeFries RS, Shimabukuro YE et al. (2006) Cropland expansion changes deforestation dynamics in the southern Brazilian amazon. Proceedings of the National Academy of Sciences of the United States of America, 103, 14637-14641.

Myers N, Mittermeler RA, Mittermeler CG, Da Fonseca GAB, Kent J (2000) Biodiversity hotspots for conservation priorities. Nature, 403, 853-858.

Nagy S, Nagy K, Szép T (2009) Potential impact of EU accession on common farmland bird populations in Hungary. Acta Ornithologica, 44, 37-44.

Nájera A (2010) Enhancing avifauna in commercial plantations. Conservation Biology, 24, 319-324.

Peppiette N (2011) The Challenge of Monitoring Environmental Priorities, the Example of HNV Farmland. DG Agriculture and Rural Development, European Commission, Brussels, Belgium.
Phalan B, Onial M, Balmford A, Green RE (2011) Reconciling food production and biodiversity conservation, land sharing and land sparing compared. Science, 333, 289-1291.

Porter J, Costanza R, Sandhu H, Sigsgaard L, Wratten S (2009) The value of producing food, energy, and ecosystem services within an agro-ecosystem. Ambio, 38, 186-193.

Rajaratnam R, Sunquist M, Rajaratnam L, Ambu L (2007) Diet and habitat selection of the leopard cat (prionailurus bengalensis borneoensis) in an agricultural landscape in Sabah, Malaysian Borneo. Journal of Tropical Ecology, 23, 209-217.

Reid WV, McNeely JA, Tunstall DB, Bryant DA, Winograd M (1993) Biodiversity Indicators for Policy Makers. World Resources Institute (WRI), Washington, D.C., USA.

Riffel S, Verschuyl J, Miller D, Wigley TB (2011) A meta-analysis of bird and mammal response to short-rotation woody crops. Global Change Biology Bioenergy, 3 313-321.

Robertson BA, Doran PJ, Loomis ER, Robertson JR, Schemske DW (2011a) Avian use of perennial biomass feedstocks as post-breeding and migratory stopover habitat. PLOS ONE, 6, e16941.

Robertson BA, Doran PJ, Loomis LR, Robertson JR, Schemske DW (2011b) Perennial biomass feedstocks enhance avian diversity. Global Change Biology Bioenergy, 3, 235-246.

Rowe RL, Hanley ME, Goulson D, Clarke DJ, Doncaster CP, Taylor G (2011) Potential benefits of commercial willow short rotation coppice (SRC) for farm-scale plant and invertebrate communities in the agri-environment. Biomass and Bioenergy, 35, 325-336

Sage R, Cunningham M, Haughton AJ, Mallott MD, Bohan DA, Riche A, Karp A (2010) The environmental impacts of biomass crops, use by birds of miscanthus in summer and winter in southwestern England. Ibis, 152, 487-499.

Sala OE, Sax D, Leslie H (2009) Biodiversity consequences of biofuel production. In Biofuels, Environmental Consequences and Interactions with Changing Land Use. Proceedings of the Scientific Committee on Problems of the Environment (SCOPE) International Biofuels Project Rapid Assessment (eds Howarth RW, Bringezu S), pp. 127-137. 22-25 September 2008, Gummersbach, Germany. Cornell University, Ithaca, NY, USA.

Sano EE, Rosa R, Brito JLS, Ferreira LG (2010) Land cover mapping of the tropical savanna region in Brazil. Environmental Monitoring and Assessment, 166, 113-124.

Schrag AM, Zaccagnini ME, Calamari N, Canavelli S (2009) Climate and land-use influences on avifauna in central Argentina, broad-scale patterns and implications of agricultural conversion for biodiversity. Agriculture, Ecosystems \& Environment 132, 135-142.

Schulz U, Brauner O, Gruß H (2009) Animal diversity on short-rotation coppices - a review. Landbauforschung-vTI Agriculture and Forestry Research 59, 171-182.

Semere T, Slater FM (2007a) Ground flora, small mammal and bird species diversity in miscanthus (Miscanthus $\times$ giganteus) and reed canary-grass (phalaris arundinacea) fields. Biomass and Bioenergy, 31, 20-29.

Semere T, Slater FM (2007b) Invertebrate populations in miscanthus (Miscanthus $\times$ giganteus) and reed canary-grass (phalaris arundinacea) fields. Biomass and Bioenergy, 31, 30-39.

Smeets E, Weterings R (1999) Environmental Indicators, Typology and Overview. Technical report No. 25. European Environment Agency, Copenhagen, Denmark.

Smeets E, Junginger M, Faaij APC, Walter A, Dolzan P, Turkenburg W (2008) The sustainability of Brazilian ethanol-an assessment of the possibilities of certified production. Biomass and Bioenergy, 32, 781-813.

Spangenberg JH, Martinez-Alier J, Omann I, Monterroso I, Binimelis R (2009) The DPSIR scheme for analyzing biodiversity loss and developing preservation strategies. Ecological Economics, 69, 9-11.

Sparovek G, Berndes G, de Oliveira G, Pereira BA, Fröhlich Klug IL (2012) The revision of the Brazilian forest act, increased deforestation or a historic step towards balancing agricultural development and nature conservation? Environmental Science \& Policy, 16, 65-72.

Stoms DM, Davis FW, Jenner MW, Nogeire TM, Kaffka SR (2012) Modeling wildlife and other trade-offs with biofuel crop production. Global Change Biology Bioenergy, 4, 330-341.

Tscharntke T, Clough Y, Wanger TC (2012) Global food security, biodiversity conservation and the future of agricultural intensification. Biological conservation, 151, 53-59.

Turner EC, Foster WA (2009) The impact of forest conversion to oil palm on arthropod abundance and biomass in Sabah, Malaysia. Journal of Tropical Ecology, 25, 23-30

Vačkár D, ten Brink B, Loh J, Baillie JEM, Reyers B (2012) Review of multispecies indices for monitoring human impacts on biodiversity. Ecological Indicators, 17 $58-67$ 
Verweij PA, Schouten M, van BP, Triana J, van dLK, Hess S (2009) Keeping the Amazon Standing, A Matter of Values. WWF-Netherlands, Zeist, the Netherlands.

Visseren-Hamakers IJ, Glasbergen P (2007) Partnerships in forest governance. Global Environmental Change, 17, 408-419.

Volpato GH, Prado VM, Anjos L (2010) What can tree plantations do for forest birds in fragmented forest landscapes? A case study in southern Brazil. Forest Ecology and Management, 260, 1156-1163.

Walter A, Dolzan P, Quilodrán O, De Oliveira JG, Da Silva C, Piacente F, Segerstedt A (2011) Sustainability assessment of bio-ethanol production in Brazil considering land use change, GHG emissions and socio-economic aspects. Energy Policy, 39, 5703-5716.

Werling BP, Meehan TD, Robertson BA, Gratton C, Landis DA (2011) Biocontrol potential varies with changes in biofuel crop plant communities and landscape perenniality. Global Change Biology Bioenergy, 3, 347-359.

Wicke B, Verweij PA, van Meijl H, van Vuuren DP, Faaij APC (2012) Indirect land use change, review of existing models and strategies for mitigation. Biofuels, 3 , 87-100.

Wiens J, Fargione J, Hill J (2011) Biofuels and biodiversity. Ecological Applications, 21, 1085-1095.

Woodcock BA, Redhead J, Vanbergen AJ et al. (2010) Impact of habitat type and landscape structure on biomass, species richness and functional diversity of ground beetles. Agriculture, Ecosystems \& Environment, 139, 181-186.
Wunder S, Engel S, Pagiola S (2008) Taking stock, a comparative analysis of payments for environmental services programs in developed and developing countries. Ecological Economics, 65, 834-852.

WWF (2012) Living planet report 2012 - biodiversity, biocapacity and making better choices.

\section{Supporting Information}

Additional Supporting Information may be found in the online version of this article:

Appendix S1. Describes the main biodiversity indicators used in the selected publications as well as other key indicators used in biodiversity research. 